\title{
Phytochrome gene expression studies: PHYE is required for FR-induced expression of PHYA and PHYD suppresses expression of PHYA
}

\author{
Umidjon Shapulatov ${ }^{1,3}$, Mara Meisenburg ${ }^{1}$, Mark van Hoogdalem $^{1,4}$, Alexander van Hall ${ }^{1}$, Wim van leperen ${ }^{2}$, \\ Maarten van Wassenaar ${ }^{2}$ and Alexander van der $\mathrm{Krol}^{1, *}$
}

\footnotetext{
${ }^{1}$ Laboratory of Plant Physiology, Wageningen University \& Research, Droevendaalsesteeg 1, 6708 PB Wageningen, The Netherlands; ${ }^{2}$ Horticulture and Product Physiology, Department of Plant Sciences, Wageningen University and Research, Droevendaalsesteeg 1, 6708 PB Wageningen, The Netherlands; ${ }^{3}$ Faculty of Biology, National University of Uzbekistan, University street 4, 100174 Tashkent, Uzbekistan; ${ }^{4}$ Business Unit Greenhouse Horticulture, Wageningen University \& Research, Droevendaalsesteeg 1, 6708PB Wageningen, The Netherlands

"Correspondence: Sander.vanderkrol@wur.nl
} 


\begin{abstract}
Arabidopsis has five phytochrome (PHY) genes for sensing the Red:Far Red (R:FR) ratio in ambient light, of which PHYA has an established role in responses to FR. To study whether and how PHYs may influence each other's transcription, PHY-Luciferase reporter plants (pPHYA:LUC, pPHYB:LUC, pPHYC:LUC, pPHYD:LUC and pPHYE:LUC) were constructed. Subsequently, reporter lines representative for each PHY were crossed into each of the five single phymutant backgrounds. Reporter activities in WT and phy mutant was studied under diurnal mixed (R, B, FR), R, FR or B LED light in seedling or rosette plants. Both PPHYA:LUC and PPHYB:LUC show strong induction under FR. Full FR upregulation of both PHYA and PHYB is dependent on PHYE, identifying PHYE as a novel sensor for FR light responses. Results also show that PHYA expression is strongly suppressed by PHYD. Results were confirmed for expression of endogenous PHYA and PHYB, albeit with different dynamics compared to the LUC reporters. Profiling of PPHYA:LUC and PPHYB:LUC reporters suggest gating of FR responses. Manipulation of PHY expression levels by FR may provide a novel basis for manipulating plant growth in controlled environments.
\end{abstract}

Key words: PHYTOCHROME, LED, Luciferase reporter plants, transcription 
bioRxiv preprint doi: https://doi.org/10.1101/2021.06.20.449137; this version posted June 22, 2021. The copyright holder for this preprint (which was not certified by peer review) is the author/funder. All rights reserved. No reuse allowed without permission. 


\section{1}

2

3

4

5

6

7

8

9

10

\section{Introduction}

The most important photoreceptors that control plant growth as function of the Red (R) and Far-Red (FR) light spectrum are a family of phytochrome (PHY) genes, which in Arabidopsis consist of PHYA-PHYE (Bae and Choi 2008). Phytochromes are produced in the inactive red $(R)$ light absorbing Pr form. Upon perception of red light the inactive $\mathrm{Pr}$ state of phytochromes changes to the active Pfr state to trigger responses in both the cytosol (Paik, Yang et al. 2012) and in the nucleus (Nagy and Schafer 2002, Nagatani 2004, Kevei, Schafer et al. 2007, Van Buskirk, Decker et al. 2012, Klose, Viczian et al. 2015). In the nucleus phytochrome protein interacts with multiple Phytochrome Interacting Factors (PIFs) to mediate light transcriptional responses (Huq, Al-Sady et al. 2004, Castillon, Shen et al. 2007, Leivar and Quail 2011). While phytochromes are activators, Phytochrome Interacting Factors (PIFs) are considered repressors of photomorphogenesis, because the interaction of phytochrome Pfr with PIFs promotes their turnover (Park, Park et al. 2012, Xu, Paik et al. 2015). The interaction between phytochromes and PIFs do not only result in degradation of the $\mathrm{PIFs}$, but also in co-degradation of the phytochrome protein. Indeed, the function of Pfr in the nucleus is controlled by multiple nuclear factors that are involved in nuclear Pfr stability (Monte, Tepperman et al. 2004, Khanna, Shen et al. 2007, Al-Sady, Kikis et al. 2008, Leivar, Monte et al. 2008, Leivar and Quail 2011, Ni, Xu et al. 2013). It has been shown that PIFs regulate phyB-E protein stability through COP1/DET/FUS (Jang, Henriques et al. 2010). In addition, PIFs and PHYs interact with a CUL3-based E3 ubiquitin ligases complex containing the Bric-a-Brac/Tramtrack/Broad Complex (BTB)-domain containing substrate adaptor Light-Response (LRB). Presumably PIFs and PHY are co-degraded by interaction between a CUL3-LRB-PIF complex and a CUL3-LRB-PHY complex, through dimerization of the LRBs (Christians, Gingerich et al. 2012). Translocation of PHY proteins into nucleus is required for the nuclear signaling and the translocation of PHYA Pfr protein into the nucleus is controlled by the FAR-RED ELONGATED HYPOCOTYL 1 (FHY1) AND FHY1-LIKE (FHL) (Genoud, Schweizer et al. 2008). PHYs also have a function in the cytosol where they control translation of specific mRNAs (Paik, Yang et al. 2012). The stability of the pool of cytosolic Pfr is regulated by cytosolic factors, explaining why the dynamics of nuclear PIF protein turnover and total PHY protein turnover may not be the same.

Transcription of PHY genes and translation of the PHY mRNAs determine the actual pool of phytochrome protein that is available for PHY protein signaling. Understanding transcriptional regulation of phytochrome genes is therefore integral part of understanding overall phytochrome action. Phytochrome genes are regulated by the circadian clock (Toth, Kevei et al. 2001), while in turn the clock is entrained through phytochrome signaling (Somers, Devlin et al. 1998). Genetic interactions between phytochromes affect germination, hypocotyl elongation and flowering, but this was not correlated to possible effects on PHY gene transcription (Sanchez-Lamas, Lorenzo et al. 2016). Recently it was shown that the promoter of PHYA is targeted by PIF4 and PIF5 (Seaton, Toledo-Ortiz et al. 2018), which potentially couples PHYA transcription to R:FR light conditions, as R:FR conditions determine the interaction between PHYB and PIF4/5 and the stability of these proteins (Lorrain, Allen et al. 2008, Foreman, Johansson et al. 2011).

In the studies on phytochrome action the effects of a given light treatment on PHY promoter activities are usually ignored. However, whether this is always justified under day light conditions or under artificial LED light with its unnatural spectral composition of LED lights requires verification. Indeed, there is no comprehensive and systematic analysis of PHY gene transcription as function of (LED) light quality. Therefore, we investigated PHY promoter activity 
as function of different LED light conditions at different developmental stages and as function of individual phytochromes. Dynamic transcriptional responses in planta was monitored using firefly luciferase (LUC) reporter lines (Millar, Short et al. 1992). The pPHYA:LUC, pPHYB:LUC, pPHYC:LUC, pPHYD:LUC and pPHYE:LUC reporter lines were crossed into each of the single phytochrome mutant backgrounds, resulting in a total of 30 reporter lines. Results show that interactions between phytochromes at the transcription level change from seedling to mature rosette stage. The diurnal PPHY:LUC activity was monitored in response to day-time R, FR or B LED light, showing strong upregulation of pPHYA-LUC and pPHYB-LUC activity under FR. Moreover, this induction by FR was not dependent on the classical FR light sensor PHYA. Full FR-induction of PHYA and PHYB under FR depends on PHYE, thus identifying PHYE as novel sensor for FR. Similarly, PHYE affected expression of endogenous PHYA and PHYB under FR. The studies thus show unexpected complex PHY-interaction in the regulation of PHY gene expression.

\section{Materials and methods}

Plant materials and growth conditions.

Seeds of Arabidopsis thaliana T-DNA insertional mutant lines were obtained from the Nottingham Arabidopsis Stock Centre (NASC, University of Nottingham, UK). The following lines were used in our work: WT (Col-0), phyA-T(NASC: N661576), phyB-9 (Reed, Nagpal et al. 1993), phyC-2 (N66036), phyD (N676270), phyE-T (N671700). All phytochrome mutants are in Col-O background. The phy T-DNA insertion mutants were validated as homozygous insertion mutant by PCR of genomic DNA using Salk T-DNA and gene specific primers (Table S1). For Luminator (van Hoogdalem, Shapulatov et al. 2021) experiments, seeds were sawn on MS-0.8\% agar plates (Murashige-Skoog medium 0.22g/L, $8 \mathrm{~g} / \mathrm{L}$ plant agar Duchefa), stratified in the dark for three days at $5^{\circ} \mathrm{C}$, after which they were sown on $4 \times 4 \times 4 \mathrm{~cm}$ rockwool blocks (Grodan, Roermond, The Netherlands) soaked in Hyponex nutrient solution (Unifarm, Wageningen, The Netherlands). Plants were pre-grown in a climate chamber $\left(12 \mathrm{hL} / 12 \mathrm{hD} ; 22^{\circ} \mathrm{C}\right.$; relative humidity $(\mathrm{RH})$ at $\left.65 \%\right)$. Directly before transfer to LUMINATOR, reporter plants were watered by soaking the rockwool blocks in Hyponex solution, which allows for growth for up to 6 days without additional watering. Light conditions in LUMINATOR cabinet are described below.

\section{PHY-LUC reporter cloning and construction homozygous reporter lines}

Construction of the pPHY:LUC reporter genes using $\sim 2 \mathrm{~kb}$ upstream promoter fragments of either PHYA, B, C, D or PHYE is described in (Toth, Kevei et al. 2001). Binairy vectors containing these reporter genes were kindly donated by the group of Prof. Nagy.

Arabidopsis Col-0 plants were transformed by floral dip transformation (Zhang, Henriques et al. 2006) and positive transformants were selected based on Luc activity. Representative homozygous lines were crossed into the different phytochrome mutant backgrounds. For all progeny homozygous for the pPHY:LUC reporter, the homozygous phy- 
71

mutant genotype was confirmed by PCR and $\mathrm{T}_{4}$ plant homozygous for both the phytochrome mutation and the respective PPHY:LUC reporter were used.

\section{In planta LUC reporter activity measurements in LUMINATOR}

LUC activity in the different PPHY:LUC reporter plants was measured in a custom built LUMINATOR cabinet containing a high performance PIXIS: 1024 CCD camera (Princeton Instruments, Roper technologies, Sarasote, FL, USA) fitted with a $35 \mathrm{~mm}$ f/1.4 Nikkor SLR lens (Nikon, Shinjuku, Tokyo, Japan). Plants were pre-sprayed with $1 \mathrm{mM}$ D-luciferin (Promega, Fitchburg, WI, USA) one day before imaging to deplete accumulated LUC (de Ruijter, Verhees et al. 2003). For multiple day measurements plants were sprayed daily with $1 \mathrm{mM}$ D-luciferin (Promega, Fitchburg, WI, USA) at 10 am. Plants were acclimated to conditions in LUMINATOR for one day. LUC activity images were taken every 30 minutes with an exposure time of 7 minutes, during which LED illumination is switched off. Light from chlorophyll fluorescence of plants was blocked by using a ZBPB074 Bandpass Filter (Asahi Spectra, Sumida, Tokyo, Japan).

Light conditions during diurnal LUC activity imaging

Imaging of ff-LUC activity in plants is under mixed LEDs, emitting R (590-660nm), B (420-500nm) and FR 680-760). In addition, a ramping in $\mathrm{R}$ intensity and $\mathrm{R}$ :FR ratio was used to mimic natural morning and evening light light conditions. The light intensity during 2 hours ramping at start-day and end-day is $33 \mu \mathrm{mole} \mathrm{m}^{-2} \mathrm{~s}^{-1}$ and during the remaining hours of the photoperiod $90 \mu$ mole $\mathrm{m}^{-2} \mathrm{~s}^{-1}$. Photosynthetically active radiation (PAR) intensity was 25 and $80 \mu \mathrm{mole} \mathrm{m}^{-2} \mathrm{~s}^{-1}$ respectively. The ratio $B: R: F R$ light during ramping is 1:2:1 and during the remaining hours of the photoperiod 3:6:1.

The Red light treatments were at $80 \mu$ mole $\mathrm{m}^{-2} \mathrm{~s}^{-1}$ of pure Red light, the FR light treatment was at $430 \mu \mathrm{mole} \mathrm{m}^{-2} \mathrm{~s}^{-1}$ of FR LED light and the Blue light treatment was at $30 \mu$ mole $\mathrm{m}^{-2} \mathrm{~s}^{-1}$ of blue light. The R>FR step gradient light treatment consists of 3 hours R:FR $=8,3$ hours R:FR $=1$ (mild shade), 3 hours R:FR $=0.5$ (shade) and 3 hours R:FR=0.2 (deep shade). PAR intensity was $80-85 \mu$ mole $\mathrm{m}^{-2} \mathrm{~s}^{-1}$ during all shade conditions. Light quality/intensity was measured the using Flame-T spectroradiometer (Ocean Optics, Duiven, The Netherlands). Relative luminescence was quantified in Image J (imagej.nih.gov/ij) as described before (Shapulatov, van Hoogdalem et al. 2018, van Hoogdalem, Shapulatov et al. 2021).

\section{Quantitative RT-PCR.}

Total RNA was isolated from 3 weeks old rosettes that placed under mixed LED for 1 day for acclimatization and the next the day, plants were exposed to far-red light $\left(430 \mathrm{umol} / \mathrm{m}^{2} \mathrm{~s}\right)$. rosettes were harvested at the indicated times. mRNA and cDNA synthesis were as described (van Hoogdalem, Shapulatov et al. 2021). qRT-PCR for quantification of endogenous PHY genes on a CFX Connect Real-time system machine (BioRad, CA, USA). Primer sequences used can be 
bioRxiv preprint doi: https://doi.org/10.1101/2021.06.20.449137; this version posted June 22, 2021. The copyright holder for this preprint (which was not certified by peer review) is the author/funder. All rights reserved. No reuse allowed without permission.

103 found in Table S1. Statistical analysis of the qPCR data was carried out in RStudio (3.6.0). A 2-way ANOVA was used to 104 analyse the qPCR data followed by a Least Significant Different (LSD) post-hoc test (agricolae 1.3-5, R package). The

105 datasets for the PHYA and PHYB activity were first log transformed to meet the assumptions of the 2-way ANOVA.

106

107

108 


\section{Results}

In order to study the expression of the five phytochrome genes (PHYS) of Arabidopsis in WT and phytochrome mutant

112 backgrounds, the upstream 2-2.5 kb promoter of each of the five PHY genes was fused to the firefly luciferase (LUC) coding sequence in binary expression vectors (Toth, Kevei et al. 2001), resulting in five PPHY:LUC reporter constructs. The different PPHY:LUC reporter constructs were introduced into Arabidopsis WT (Col-O) by the agrobacterium mediated floral dip transformation (Zhang, Henriques et al. 2006). For each of the pPHY:LUC reporters a minimum of ten primary transformants were screened for luciferase activity and one representative transformed plant was selected and developed into a homozygous reporter line expressing either pPHYA:LUC, pPHYB:LUC, pPHYC:LUC, pPHYD:LUC or pPHYE:LUC. Subsequently, each of the five homozygous PPHY:LUC reporter plants was crossed to each of five single phy-mutant plants. Phytochrome mutant backgrounds were selected based on seedling growth phenotype under specific light conditions and PCR analysis of genomic DNA using specific primers (Table S1) (Nagatani, Reed et al. 1993, Hennig, Funk et al. 1999, Balasubramanian, Sureshkumar et al. 2006, Chen, Sonobe et al. 2013). By crossing the pPHY:LUC reporter into the different phy-mutant backgrounds, the relative expression of the LUC reporter in WT and mutant can be compared directly, since the reporter is in same chromosomal location with identical 'position' effects on transgene expression. The pPHY:LUC reporter lines and constructs are listed in Table S2. Fig. 1 shows representative images of the pPHY:LUC reporter activity in WT in three week old rosette plants. The relative level of LUC activity is not the same for the different PHY reporters. At the rosette stage the PHYA and PHYC promoters show the strongest transcriptional activity, while transcription from the PHYE promoter is very weak. three developmental stages the LUC activity imaging was at $11 \mathrm{am}$, close to the maximum phase of pPHY:LUC reporters in seedlings (Toth, Kevei et al. 2001). The average relative LUC activity per seedling/plant was quantified for each of the reporter lines (Fig. 2). The results indicate that especially in 7-day-old seedlings for many PPHY-LYC reporters the activity is significantly increased in a phy-mutant background, indicating that at early stages of development different phytochromes are involved in repression of transcription of the PPHY-LUC reporters (Fig. 2A-E). However, as plants mature, this genetic interaction between phytochromes at the transcription level diminishes (Fig. 2A-E). Most remarkable is the consistent elevated level of pPHYA-LUC expression in the phyD mutant background, indicating that PHYD is a constitutive suppressor of PPHYA-LUC transcription. As plant mature the genetic interactions between the different phytochromes diminishes, but is still apparent for the suppression by PHYB on PPHYA-LUC, the suppression by PHYB, PHYC, PHYD and PHYE on PPHYB-LUC and suppression by PHYA, PHYB and PHYC on PPHYD-LUC

141 (Fig. 2, 24 day old plants). In contrast, full expression of pPHYC-LUC in mature plants requires PHYB (Fig. 2C, 14 and 24 dayold plants). 
To determine the PPHY:LUC activity in WT under different light conditions, plants were imaged in Luminator (van Hoogdalem, Shapulatov et al. 2021) for four days. After one day acclimation, LUC activity was imaged in plants under 12hrR/12D, followed by $12 \mathrm{hrFR} / 12 \mathrm{D}$ and finally $12 \mathrm{hrB} / 12 \mathrm{D}$, using either $\mathrm{R}, \mathrm{B}$ or FR LED light during the day. The pPHY:LUC activity images were obtained every 30 minutes. This was done for 7-day old plants, 14-days old plants and when plants were 25-day old. Qualitatively the responses of the different PPHY:LUC reporters are similar at these three stages of development and results of the expression profiles in 14 day old plants are shown in Figure 3 . Most pPHY:LUC reporters do not show a strong response to the R photoperiod, except for PPHYC:LUC which is induced under R. Also, pPHYC:LUC shows a consistent transient increase in activity at the day-night transition following all photoperiods (Fig. 3). Most remarkable is the strong and immediate upregulation of PPHYB:LUC under FR light following the dark period of the night, reaching a peak expression almost 10-fold higher then under $\mathrm{R}$ light. During the night following FR, both expression of pPHYB:LUC and pPHYA:LUC show an initial rapid decline. Expression of pPHYA:LUC is also upregulated by FR light but in a more gradual way, reaching a 6 -fold higher expression at the end of the FR photoperiod compared to under R. Moreover, only PPHYC:LUC shows a transient increase in activity at the daynight transition following all photoperiods. The other PPHY:LUC reporters were not induced by FR, or showed a decline of expression under FR. Only PPHYB-LUC and PPHYC-LUC show a strong response to B during the day (Fig. 3). Overall, results show that light quality may change the expression level of some of the phytochrome genes and thus light quality changes the potential pool of phytochrome protein that may participate in light signaling. Note that some of the fine structure in the LUC activity profiles during the day is most likely due to renewed spraying of luciferin and some leaf hyponastic movement. suggests the involvement of PHYA, which is the classical sensor for FR light responses (Whitelam, Johnson et al. 1993, Yanovsky, Casal et al. 1997, Fankhauser 2001). To determine the role of individual phytochromes in expression of pPHYB:LUC under different light conditions (R/FR/B, R, FR or B LED light), the pPHYB:LUC activity was monitored in the different phytochrome mutant backgrounds (Fig. S1). As example, here we show results for PPHYB:LUC in WT and different phytochrome mutants under FR and B (Figure 4). The induction of PPHYB:LUC under FR is significantly reduced in the phyB and the phyE mutant background, indicating that in context of transcriptional regulation of PPHYB:LUC expression the PHYB and PHYE act as a FR sensor. In contrast, the classical FR sensor PHYA has little effect on PPHYB:LUC activity under FR (Fig. 4). Most phytochromes do not affect the response of pPHYB:LUC to B, except for PHYC, which represses pPHYB:LUC activity in WT (Fig. 4). 
179

180

181

182

183

184

185

186

187

188

189

190

191

192

193

194

195

196

197

198

199

200

201

202

203

204

205

206

207

208

209

210

211

212

213

pPHYB:LUC under B in WT ZT=3 hr, in phyB mutant ZT=7 hr, in phyC ZT= 2 hr; Fig. 4). Expression of pPHYB:LUC in the phyB mutant background under mixed or R light is increased compared to in WT, but decreased under FR and B LED light compared to in WT (Fig. S1). This indicates that the effect of PHYB on its own promoter activity is dependent on light conditions and may switch from a repressor interaction (under mixed and $\mathrm{R}$ light) to activator interaction (under FR and B) (Fig. S1 and Fig. 4).

\section{PPHY-LUC response to "shade" depends on time of the day}

To investigate the phytochrome gene expression as function of shade light conditions, pPHY:LUC reporter activity was imaged in 25-day old WT rosette plants placed under varying ratio's of R:FR light. The five sets of WT pPHY:LUC reporter plants were placed in LUMINATOR to adapt for two days to diurnal mixed LED light (R,B,FR). After the night of the second day, the photoperiod was started using 3 hours of $R$ light combined with low level of $F R$ ( $R: F R=8$ ). Subsequently, every 3 hours the $R$ level remained the same, but dosage of FR was increased going from $R: F R=8$ to $R: F R=1$, to $R: F R=0.5$ and finally ending the day with 3 hours of $R: F R=0.2$, which mimics deep shade conditions. After the night following these 4 blocks of increasing shade light conditions, the next day, the same blocks of R+FR LED light were given in reverse order, starting the day with $R: F R=0.2$ and ending the day with $R: F R=8$. The different $p P H Y: L U C$ reporters show different responses to the shade treatments (Fig. 5). Both pPHYA:LUC and pPHYB:LUC show little response to the day under mixed $R, F R, B$ LED and no response to $3 \mathrm{hr} R: F R=8$ (Fig. 5). Under $R: F R=1 \mathrm{pPHYB}: L U C$ shows an direct transcriptional response, while for pPHYA:LUC and pPHYC:LUC a transcriptional response only starts near the end of three hour R:FR=1 (Fig. 5). In contrast PPHYD:LUC expression is down regulated during this light treatment. This is consistent with our discovery that PHYD is a suppressor of PHYA (Fig. 2) and suggests that part of the upregulation of PHYA may be caused by downregulation of PHYD under increasing shade conditions. However, the following day when light treatments are given in reverse order, pPHYD:LUC activity shows an increase at the end of $3 \mathrm{hr} R: F R=0.2$, which is not mirrored by a decline in PPHYA:LUC activity (Fig. 5). During the night, expression of PHYA, PHYB and PHYC initially decline with different rates, which is less rapid than the decline in pPHY:LUC expression after pure FR (Fig. 3). Also, after pure FR expression declines to "normal” levels as seen under WL, mixed LED or B (Fig. 3), while after the R+FR light treatments the expression of pPHYA:LUC and pPHYB:LUC remains high throughout the night (Fig. 5).

When light treatment goes from deep shade to mild shade, only pPHYB:LUC shows a direct upregulation under $R: F R=0,2$, levels off at $R: F R=0,5$ and subsequently decreases under $R: F R=1$ and 8 . While pPHYA:LUC shows the strongest response to $R: F R=0,2$ at end of day, when this shade condition is given at the start of the day pPHYA:LUC shows no response and only increases in activity at R:FR=0,5 or higher (Fig. 5). In general pPHYC:LUC decreases when R:FR increases, while in general PPHYD:LUC shows the opposite response and shows decrease in activity when R:FR increases. Overall, the results indicated changes in PPHY:LUC activity as function of shade, but dependent on time of day shade conditions are given. Subsequently the role of individual phytochromes is in the shade response of the different PPHY:LUC reporters was determined. 
To determine the role of each of the five phytochromes in the response to different R:FR ratios, pPHY:LUC reporter activities were quantified in all phytochrome mutant backgrounds (Fig. S2A-E). Here only the big effects on PHYA and PHYB expression are discussed. Expression of PPHYA:LUC is mostly affected by PHYD and PHYE: expression of PPHYA:LUC is much increased in the phyD mutant, while the upregulation of pPHYA:LUC under increasing FR is absent in the phyE mutant background (Fig. 6). This confirms a specific role for PHYE in FR light sensing in the regulation of PHYA gene expression. In contrast, the classical sensor for FR responses PHYA had only a small effect on FR-induction of PHYA-LUC (Fig. S2). The PPHYB:LUC activity is mostly affected by PHYB itself (Fig. S2B). The effect of PHYC, PHYD and PHYE on PHYB expression is conditional: they have little effect on PPHYB:LUC activity when going from high R:FR to low R:FR, but these phytochromes act as suppressor of pPHYB:LUC expression when light changes from low R:FR to high R:FR (Fig. S2B).

Results for the PHY:LUC reporters reflect the activity of endogenous transcription factors on the inserted transgenes.

To determine if the reporter activity also reflecst activity of the endogenous PHY genes some of the strong effects of shows a different dynamics of induction of endogenous PHYA under FR, indicating that the normal context of the PHYA gene is far more buffered against effects of FR than the PPHYA:LUC reporter. However, endogenous PHYA is induced after $10 \mathrm{hr}$ of FR and this induction is absent in the phyE mutant, confirming the interaction as shown for the PPHYA:LUC reporter. Moreover, also the strong suppression by PHYD of PHYA expression is confirmed for the endogenous PHYA gene (Fig. 7A). The endogenous PHYB gene shows rapidly upregulation under FR and this upregulation is reduced in the phyE mutant for the early response peak, confirming a role for PHYE in FR responses for PHYB expression (Fig. 7B).

\section{Discussion}

\section{Mutual transcriptional regulation also at the basis of complex interaction between $\mathrm{PHYS}$}

The role of the different phytochrome gene family members of the Arabidopsis has mostly been studied for complex genetic interactions between the different Arabidopsis phytochrome genes (Sanchez-Lamas, Lorenzo et al. 2016). Here we have revealed a potential basis of these complex interactions by revealing that phytochrome genes

242 influence each other's transcription. The interactions a re complex because they may depend on given light conditions.

243 For instance, the activity of PHYB on its own expression reverses depending on the light conditions: under mixed light 244 and R LED PHYB suppresses its own expression, while under FR PHYB is required for the full induction response (Fig. 5). 245 This light dependent activity is also visible in the experiment with different R:FR light treatments, which shows that 246 PHYB strongly suppresses its own gene expression under mixed LED light, but is required for the response to R plus 247 added FR light (Fig. S2B). 
The transcriptional factors that act on the pPHY:LUC reporters show a strong response in some of the single phytochrome mutants (Figs. 2, 4, 5). However, validation of the PPHYA:LUC and pPHYB:LUC reporter responses also indicates that endogenous PHYA and PHYB gene expression may be more buffered against the effect of single phytochrome mutation (Fig. 7). Nevertheless, major effects revealed by the PPHY:LUC reporters were validated for endogenous PHYA and PHYB (Fig. 7): PHYE is required for full FR induced transcription of PHYA and PHYB and PHYD represses PHYA transcription.

\section{PHYD is a constitutive suppressor of PHYA gene transcription}

One of the strongest and consistent interactions these studies have uncovered is the suppression of PHYA transcription by PHYD at different stages of development and under different light conditions (Figs 2,6,7). Assuming that this interaction is cell specific, this implies that PHYD is expressed in most cells that express PHYA. The biological function of this suppression of PHYA by PHYD is at present not clear. Our results are consistent with the complementary expression profiles of PHYA and PHYD in developing and dry seeds (low PHYA, high PHYD), and imbibed seeds (high PHYA and low PHYD) (Toufighi, Brady et al. 2005). The function of PHYD thus could to be to limit PHYA expression in developing seeds. PHYD can form a homodimer and heterodimers with PHYB, PHYC and PHYE (Sharrock and Clack 2004). None of the mutants of phyB, phyC or phyE show a strong effect on pPHYA:LUC expression (Fig. 2), suggesting that it may be the combined loss of PHYD homodimers and heterodimers that are responsible for the strong upregulation of PHYA expression in the phyD mutant. Future analysis will have to show how PHYA expression is affected in double and triple PHY mutants. The higher expression level of PHYA in the phyD mutant background may relate to the different phenotypes that have been described for the Arabidopsis phyD mutant (Christians, Gingerich et al. 2012, Sanchez-Lamas, Lorenzo et al. 2016).

\section{Gating of the FR-induced PHY transcriptional response}

The strong induction of both PHYA and PHYB is not only an artifact of the unnatural pure FR light condition (Figs 3 and 4), but is also seen at more physiological levels of R:FR (Figs S4, 5 and 6). The responses to different ratios of R:FR are dependent on time of day at which they are given, with the strongest response near end of day and the strongest suppression of a FR-induced transcriptional response at the start of the day. Overall, this suggests a gating of the FR transcriptional response of PHYA and PHYB by the circadian clock and this gating coincides in gating of the rapid FR elongation response observed in seedlings (Salter, Franklin et al. 2003). Expression of phytochrome genes is seedlings is strongly regulated by the clock (Toth, Kevei et al. 2001). However, the amplitude in PHY expression by clock regulation seems to be very much reduced in mature rosetted plants (Figs 3 and 5). The reciprocal interaction between PHYs and the clock on PHY gene transcription, combined with the interactions between different PHYs on PHY gene transcription as function of light condition, may explain the different phases for the FR light responses for PHYA and PHYB. 
Phytochrome activity under different light conditions has mainly been studied for signalling downstream of $\mathrm{PHY} \mathrm{Pfr}^{\mathrm{Pr}}$, which is both a function of the total phytochrome protein pool and the equilibrium between active $\mathrm{PHP} \mathrm{Pfr}^{\mathrm{pr}}$ and inactive $\mathrm{PHY}^{\mathrm{Pr}}$. Although it is well established that the fraction of activated PHY protein is determined by R:FR ratio, here we have shown that under specific light conditions also the input of PHY protein may change. The increased transcription of PHYA and PHYB in response to FR may increase the total PHYA and PHYB protein pool. Potentially, this may compensate a little for the shift in the equilibrium between $\mathrm{PHY}^{\mathrm{Pfr}}$ and $\mathrm{PHY} \mathrm{Pr}^{\mathrm{Pr}}$ under FR towards inactive $\mathrm{PHY} \mathrm{Y}^{\mathrm{Pr}}$. In addition, an increased PHYA and PHYB protein pool in response to FR increases the potential for light signaling when conditions favour activation of PHY protein again. This could have potential applications in manipulating PHY action in greenhouses to steer crop performances.

Phytochrome interactions studies have revealed that PHYC may form heterodimer with PHYB and PHYD and that PHYC may not exist as homodimer (Clack, Shokry et al. 2009). The relative high expression of PHYC compared to that of PHYB, PHYD and especially PHYE (which is expressed at very low levels), suggest that PHYB and PHYD may increase in the pool of PHYB/D and PHYB/E heterodimers. The induction of PHYB expression under FR is strongly affected by PHYB and PHYE, but not PHYC or PHYD. This could suggest that the induction of PHYB expression under FR may be mostly through PHYB/E heterodimers (Hofmann 2009).

The classical high irradiance response (HIR) of Arabidopis is characterized by the suppression of hypocotyl elongation. Both PHYA and PHYB are involved in this HIR response (Quail, Boylan et al. 1995), but PHYB is mostly responsible for HIR under CR light (R-HIR) (Nagatani, Kay et al. 1991, Reed, Nagpal et al. 1993) and PHYA predominantly for the HIR responses under CFR light (FR-HIR) (Hartmann 1967, Nagatani, Reed et al. 1993, Parks and Quail 1993, Whitelam, Johnson et al. 1993, Casal, Candia et al. 2014, Possart, Fleck et al. 2014). The strong induction of PHYA promoter activity under FR light may be considered as a novel FR-HIR response. However, not PHYA but PHYE is involved in this

309 FR-HIR induction of PHYA gene activity (Figs 6 , 7). Phytochromes are classified as either Type I, which are activated by 310 far-red light, or Type II that are activated by red light (Li, Li et al. 2011), although phytochrome Type I and Type II may 311 also be defined by the phytochrome protein stability in light. For Arabidopsis only PHYA has been classified as a Type I 312 phytochrome, as it is responsible for many FR light induced responses and is instable in the light. With the extension 313 of FR-HIR responses beyond seedling de-etiolation to PHY gene expression under FR, the classification of Arabidopsis 

PHYC were already formed before the formation of gymnosperms, as both monocotyledons and dicotyledons contain representatives of PHYA, PHYB, and PHYC. In dicotyledonous plants, duplications of the PHYB progenitors resulted in 318 the PHYE subfamily and, specifically in Arabidopsis, another duplication event of PHYB resulted in PHYD (Clack,

319 Mathews et al. 1994). In contrast, grasses lack the PHYD and PHYE members of the PHYB subfamily. While the PHYC in Arabidopsis is a type II phytochrome, in rice, PHYC mediates FR-HIR de-etiolation and therefore could be considered a Type I phytochrome (Takano, Inagaki et al. 2005). Future research will have to show whether or how the effect of individual PHY genes in dicots and monocots relates to mutual transcriptional regulation of PHY gene expression and how this modulates phenotypic responses to different light conditions. 


\section{References}

Al-Sady, B., E. A. Kikis, E. Monte and P. H. Quail (2008). "Mechanistic duality of transcription factor function in phytochrome signaling." Proc Natl Acad Sci U S A 105(6): 2232-2237.

Bae, G. and G. Choi (2008). "Decoding of light signals by plant phytochromes and their interacting proteins." Annu Rev Plant Biol 59: 281-311.

Balasubramanian, S., S. Sureshkumar, M. Agrawal, T. P. Michael, C. Wessinger, J. N. Maloof, R. Clark, N. Warthmann, J. Chory and D. Weigel (2006). "The PHYTOCHROME C photoreceptor gene mediates natural variation in flowering and growth responses of Arabidopsis thaliana." Nat Genet 38(6): 711-715.

Casal, J. J., A. N. Candia and R. Sellaro (2014). "Light perception and signalling by phytochrome A." J Exp Bot 65(11): 2835-2845.

Castillon, A., H. Shen and E. Huq (2007). "Phytochrome Interacting Factors: central players in phytochromemediated light signaling networks." Trends Plant Sci 12(11): 514-521.

Chen, J., K. Sonobe, N. Ogawa, S. Masuda, A. Nagatani, Y. Kobayashi and H. Ohta (2013). "Inhibition of arabidopsis hypocotyl elongation by jasmonates is enhanced under red light in phytochrome $\mathrm{B}$ dependent manner." J Plant Res 126(1): 161-168.

Christians, M. J., D. J. Gingerich, Z. Hua, T. D. Lauer and R. D. Vierstra (2012). "The light-response BTB1 and BTB2 proteins assemble nuclear ubiquitin ligases that modify phytochrome $B$ and $D$ signaling in Arabidopsis." Plant Physiol 160(1): 118-134.

Clack, T., S. Mathews and R. A. Sharrock (1994). "The phytochrome apoprotein family in Arabidopsis is encoded by five genes: the sequences and expression of PHYD and PHYE." Plant Mol Biol 25(3): 413-427. Clack, T., A. Shokry, M. Moffet, P. Liu, M. Faul and R. A. Sharrock (2009). "Obligate heterodimerization of Arabidopsis phytochromes $\mathrm{C}$ and $\mathrm{E}$ and interaction with the PIF3 basic helix-loop-helix transcription factor." Plant Cell 21(3): 786-799.

de Ruijter, N. C. A., J. Verhees, W. van Leeuwen and A. R. van der Krol (2003). "Evaluation and Comparison of the GUS, LUC and GFP Reporter System for Gene Expression Studies in Plants." Plant Biology 5(2): 103115.

Fankhauser, C. (2001). "The phytochromes, a family of red/far-red absorbing photoreceptors." J Biol Chem 276(15): 11453-11456.

Foreman, J., H. Johansson, P. Hornitschek, E. M. Josse, C. Fankhauser and K. J. Halliday (2011). "Light receptor action is critical for maintaining plant biomass at warm ambient temperatures." Plant J 65(3): 441452.

Genoud, T., F. Schweizer, A. Tscheuschler, D. Debrieux, J. J. Casal, E. Schafer, A. Hiltbrunner and C. Fankhauser (2008). "FHY1 mediates nuclear import of the light-activated phytochrome A photoreceptor." PLoS Genet 4(8): e1000143.

Hartmann, K. M. (1967). "Phytochrome 730 (Pfr), the effector of the "high energy photomorphogenic reaction" in the far-red region." Naturwissenschaften 54(20): 544.

Hennig, L., M. Funk, G. C. Whitelam and E. Schafer (1999). "Functional interaction of cryptochrome 1 and phytochrome D." Plant J 20(3): 289-294.

Hofmann, N. R. (2009). "Opposites attract: some phytochromes do not form homodimers." Plant Cell 21(3): 698.

Huq, E., B. Al-Sady, M. Hudson, C. Kim, K. Apel and P. H. Quail (2004). "Phytochrome-interacting factor 1 is a critical bHLH regulator of chlorophyll biosynthesis." Science 305(5692): 1937-1941.

Jang, I. C., R. Henriques, H. S. Seo, A. Nagatani and N. H. Chua (2010). "Arabidopsis PHYTOCHROME INTERACTING FACTOR proteins promote phytochrome B polyubiquitination by COP1 E3 ligase in the nucleus." Plant Cell 22(7): 2370-2383.

Kevei, E., E. Schafer and F. Nagy (2007). "Light-regulated nucleo-cytoplasmic partitioning of phytochromes." J Exp Bot 58(12): 3113-3124. 
Khanna, R., Y. Shen, C. M. Marion, A. Tsuchisaka, A. Theologis, E. Schafer and P. H. Quail (2007). "The basic helix-loop-helix transcription factor PIF5 acts on ethylene biosynthesis and phytochrome signaling by distinct mechanisms." Plant Cell 19(12): 3915-3929.

Klose, C., A. Viczian, S. Kircher, E. Schafer and F. Nagy (2015). "Molecular mechanisms for mediating lightdependent nucleo/cytoplasmic partitioning of phytochrome photoreceptors." New Phytol 206(3): 965-971. Leivar, P., E. Monte, Y. Oka, T. Liu, C. Carle, A. Castillon, E. Huq and P. H. Quail (2008). "Multiple phytochrome-interacting bHLH transcription factors repress premature seedling photomorphogenesis in darkness." Curr Biol 18(23): 1815-1823.

Leivar, P. and P. H. Quail (2011). "PIFs: pivotal components in a cellular signaling hub." Trends Plant Sci 16(1): 19-28.

Li, J., G. Li, H. Wang and X. Wang Deng (2011). "Phytochrome Signaling Mechanisms." The Arabidopsis Book $\angle$ American Society of Plant Biologists 9: e0148.

Lorrain, S., T. Allen, P. D. Duek, G. C. Whitelam and C. Fankhauser (2008). "Phytochrome-mediated inhibition of shade avoidance involves degradation of growth-promoting bHLH transcription factors." Plant J 53(2): 312-323.

Millar, A. J., S. R. Short, N. H. Chua and S. A. Kay (1992). "A novel circadian phenotype based on firefly luciferase expression in transgenic plants." Plant Cell 4(9): 1075-1087.

Monte, E., J. M. Tepperman, B. Al-Sady, K. A. Kaczorowski, J. M. Alonso, J. R. Ecker, X. Li, Y. Zhang and P. H. Quail (2004). "The phytochrome-interacting transcription factor, PIF3, acts early, selectively, and positively in light-induced chloroplast development." Proc Natl Acad Sci U S A 101(46): 16091-16098.

Nagatani, A. (2004). "Light-regulated nuclear localization of phytochromes." Curr Opin Plant Biol 7(6): 708711.

Nagatani, A., S. A. Kay, M. Deak, N. H. Chua and M. Furuya (1991). "Rice type I phytochrome regulates hypocotyl elongation in transgenic tobacco seedlings." Proc Natl Acad Sci U S A 88(12): 5207-5211.

Nagatani, A., J. W. Reed and J. Chory (1993). "Isolation and Initial Characterization of Arabidopsis Mutants That Are Deficient in Phytochrome A." Plant Physiol 102(1): 269-277.

Nagy, F. and E. Schafer (2002). "Phytochromes control photomorphogenesis by differentially regulated, interacting signaling pathways in higher plants." Annu Rev Plant Biol 53: 329-355.

Ni, W., S. L. Xu, R. J. Chalkley, T. N. Pham, S. Guan, D. A. Maltby, A. L. Burlingame, Z. Y. Wang and P. H. Quail (2013). "Multisite light-induced phosphorylation of the transcription factor PIF3 is necessary for both its rapid degradation and concomitant negative feedback modulation of photoreceptor phyB levels in Arabidopsis." Plant Cell 25(7): 2679-2698.

Paik, I., S. Yang and G. Choi (2012). "Phytochrome regulates translation of mRNA in the cytosol." Proc Natl Acad Sci U S A 109(4): 1335-1340.

Park, E., J. Park, J. Kim, A. Nagatani, J. C. Lagarias and G. Choi (2012). "Phytochrome B inhibits binding of phytochrome-interacting factors to their target promoters." Plant J 72(4): 537-546.

Parks, B. M. and P. H. Quail (1993). "hy8, a new class of arabidopsis long hypocotyl mutants deficient in functional phytochrome A." Plant Cell 5(1): 39-48.

Possart, A., C. Fleck and A. Hiltbrunner (2014). "Shedding (far-red) light on phytochrome mechanisms and responses in land plants." Plant Sci 217-218: 36-46.

Quail, P. H., M. T. Boylan, B. M. Parks, T. W. Short, Y. Xu and D. Wagner (1995). "Phytochromes:

photosensory perception and signal transduction." Science 268(5211): 675-680.

Reed, J. W., P. Nagpal, D. S. Poole, M. Furuya and J. Chory (1993). "Mutations in the gene for the red/farred light receptor phytochrome $B$ alter cell elongation and physiological responses throughout Arabidopsis development." The Plant Cell 5(2): 147-157.

Reed, J. W., P. Nagpal, D. S. Poole, M. Furuya and J. Chory (1993). "Mutations in the gene for the red/farred light receptor phytochrome $B$ alter cell elongation and physiological responses throughout Arabidopsis development." Plant Cell 5(2): 147-157.

Salter, M. G., K. A. Franklin and G. C. Whitelam (2003). "Gating of the rapid shade-avoidance response by the circadian clock in plants." Nature 426(6967): 680-683.

Sanchez-Lamas, M., C. D. Lorenzo and P. D. Cerdan (2016). "Bottom-up Assembly of the Phytochrome Network." PLOS Genet 12(11): e1006413. 
Seaton, D. D., G. Toledo-Ortiz, A. Ganpudi, A. Kubota, T. Imaizumi and K. J. Halliday (2018). "Dawn and photoperiod sensing by phytochrome A." Proceedings of the National Academy of Sciences 115(41): 10523. Shapulatov, U., M. van Hoogdalem, M. Schreuder, H. Bouwmeester, I. Y. Abdurakhmonov and A. R. van der Krol (2018). "Functional intron-derived miRNAs and host-gene expression in plants." Plant Methods 14(1): 83.

Sharrock, R. A. and T. Clack (2004). "Heterodimerization of type II phytochromes in Arabidopsis." Proc Natl Acad Sci U S A 101(31): 11500-11505.

Somers, D. E., P. F. Devlin and S. A. Kay (1998). "Phytochromes and cryptochromes in the entrainment of the Arabidopsis circadian clock." Science 282(5393): 1488-1490.

Takano, M., N. Inagaki, X. Xie, N. Yuzurihara, F. Hihara, T. Ishizuka, M. Yano, M. Nishimura, A. Miyao, H. Hirochika and T. Shinomura (2005). "Distinct and cooperative functions of phytochromes A, B, and C in the control of deetiolation and flowering in rice." Plant Cell 17(12): 3311-3325.

Toth, R., E. Kevei, A. Hall, A. J. Millar, F. Nagy and L. Kozma-Bognar (2001). "Circadian clock-regulated expression of phytochrome and cryptochrome genes in Arabidopsis." Plant Physiol 127(4): 1607-1616.

Toufighi, K., S. M. Brady, R. Austin, E. Ly and N. J. Provart (2005). "The Botany Array Resource: e-Northerns, Expression Angling, and promoter analyses." Plant J 43(1): 153-163.

Van Buskirk, E. K., P. V. Decker and M. Chen (2012). "Photobodies in light signaling." Plant Physiol 158(1): 52-60.

van Hoogdalem, M., U. Shapulatov, L. Sergeeva, J. Busscher-Lange, M. Schreuder, D. Jamar and A. R. van der Krol (2021). "A temperature regime that disrupts clock-controlled starch mobilization induces transient carbohydrate starvation, resulting in compact growth. "J Exp Bot.

Whitelam, G. C., E. Johnson, J. Peng, P. Carol, M. L. Anderson, J. S. Cowl and N. P. Harberd (1993).

"Phytochrome A null mutants of Arabidopsis display a wild-type phenotype in white light." Plant Cell 5(7): 757-768.

Xu, X., I. Paik, L. Zhu and E. Huq (2015). "Illuminating Progress in Phytochrome-Mediated Light Signaling Pathways." Trends Plant Sci 20(10): 641-650.

Yanovsky, M. J., J. J. Casal and J. P. Luppi (1997). "The VLF loci, polymorphic between ecotypes Landsberg erecta and Columbia, dissect two branches of phytochrome A signal transduction that correspond to verylow-fluence and high-irradiance responses." Plant J 12(3): 659-667.

Zhang, X., R. Henriques, S. S. Lin, Q. W. Niu and N. H. Chua (2006). "Agrobacterium-mediated transformation of Arabidopsis thaliana using the floral dip method." Nat Protoc 1(2): 641-646. 


\section{Figure legends}

\section{Fig.1. pPHY:LUC reporter plants.}

Relative luciferase activity was captured in 28-day old rosette plants sprayed with $1 \mathrm{mM}$ luciferin-D. LUC activity image capturing was by seven minutes exposure time. pPHYC:LUC shows the highest activity, while pPHYE:LUC is a little above background.

\section{Fig.2. pPHY:LUC activity at ZT=3hr at different developmental stages}

Plants were grown in growth cabinets under fluorescent WL and sprayed with substrate luciferin (1 mM) one day and one hour before imaging. LUC activity was imaged in plants at 7, 14 and 24-26 days post germination at 11 am (ZT=3hr). A: pPHYA:LUC in WT and five phytochrome mutants; B: pPHYB:LUC in WT and five phytochrome mutants; C: pPHYC:LUC in WT and five phytochrome mutants; D: pPHYD:LUC in WT and five phytochrome mutants; E: pPHYE:LUC in WT and five phytochrome mutants (not detectable at 7 days). The relative LUC activity was quantified in ImageJ. Number of replicate plants for each reporter line: $N=9$ for $7 \mathrm{DAG}, \mathrm{N}=9$ for $14 \mathrm{DAG}$ and $\mathrm{N}=6$ for rosette plants. Error bars represent mean \pm SE. Error Bars with symbols $(* ; * * ; * *)$ indicate a significance to compare WT respective to $\mathrm{p}$ value $<0.05 ;<0.01 ;<0.001$.

\section{Fig.3. Diurnal expression profile of the pPHY:LUC reporters under diurnal 12R/12D, 12FR/12D and 12B/12D}

Plants were grown under $12 \mathrm{~L} / 12 \mathrm{D}$ and 14 days after germination seedlings were sprayed with $1 \mathrm{mM}$ luciferin. One day later plants were placed in LUMINATOR for adjustment under diurnal $R+B+F R$ for one day. Subsequently plants were exposed to light regimes 12R/12D, followed by 12FR/D and finally 12B/12D. Luciferin (1 mM) solution was sprayed once per day. LUC activity images were obtained every half hour ( $7 \mathrm{~min}$. exposure) for each full diurnal cycle. The relative LUC activity was quantified in Image and corrected for background signal. Number of replicate seedlings for each reporter line: $\mathrm{N}=6$. Error bars represent mean $\pm \mathrm{SE}$.

\section{Fig.4. pPHYB:LUC activity in WT and phytochrome mutants in $\mathbf{1 4}$ day old seedlings under FR or B}

Seeds of the PPHYB:LUC reporter lines were stratified and germinated in growth cabinets under diurnal fluorescent $W L(12 L / 12 D)$. At 14 days after germination seedlings were sprayed with substrate luciferin ( $1 \mathrm{mM}$ ) and one day later placed in LUMINATOR for adjustment under diurnal R+B+FR for one day. Then plants were exposed to light regimes of 12mixed/12D, 12R/12D, 12FR/D and finally 12B/12D. Luciferin (1 mM) solution was sprayed once per day. LUC activity images were obtained every half hour ( $7 \mathrm{~min}$. exposure) for each full diurnal cycle. The relative LUC activity is quantified in ImageJ and adjusted for background signal. Number of replicate seedlings for each reporter line: $\mathrm{N}=16$. 
Error bars represent mean \pm SE. All results are shown in Fig. S3. Here only results for pPHYB-LUC in WT and phymutants under FR and $B$ are shown.

\section{Fig.5. pPHY:LUC activity in WT rosette plants in response to changing R:FR ratios}

PPHY:LUC in WT plants were grown in growth cabinets under diurnal fluorescent WL (12L/12D) for 25 days. Reporter plants were sprayed with substrate luciferin $(1 \mathrm{mM})$ and one day later placed in LUMINATOR for adjustment under diurnal mixed $R+B+F R$ for one day. Subsequently rosette plants were exposed to $R$ light with increasing levels of $F R$ (in blocks of 3 hours), resulting in R:FR ratios of $8,1,0.5$ and 0.2 . After the following night plants were exposed to the reverse light regime. Luciferin $(1 \mathrm{mM})$ solution was sprayed once per day. LUC activity images were obtained every half hour (7 min. exposure) for each full diurnal cycle. The relative LUC activity was quantified in ImageJ and corrected for background signal. At least 7 replicate rosette plants were used for each reporter line. Error bars represent mean $\pm S E$. The vertical line indicates the day to night transition.

\section{Fig.6. pPHYA:LUC activity in WT and phyD and phyE mutant in response to changing R:FR ratios}

PPHYA:LUC in WT, phyD and phyE plants were grown in growth cabinets under diurnal fluorescent WL (12L/12D) for 25 days one day later placed in LUMINATOR for adjustment under diurnal mixed R+B+FR for one day. Subsequently rosette plants were exposed to $R$ light with increasing levels of FR (in blocks of 3 hours), resulting in R:FR ratio's of 8, 1, 0.5 and 0.2. After the following night plants were exposed to the reverse light regime. Every day once at 11AM plants were sprayed with substrate luciferin $(1 \mathrm{mM})$ solution. LUC activity images were obtained every half hour $(7 \mathrm{~min}$. exposure) for each full diurnal cycle. The relative LUC activity was quantified in ImageJ and corrected for background signal. Number of replicate seedlings for each reporter line: $N=7$. Error bars represent mean \pm SE. A: pPHYA-LUC activity in WT, phyD. B: pPHYA-LUC activity in WT and phyE. Note that for activity in phyD mutant the scale of relative LUC activity was adjusted. Black: PHYA-LUC in WT, grey: PHYA-LUC in phy mutant. (Expression of all pPHY-LUC reporter lines in WT and phy-mutants under changing R:FR is given in Fig. S4).

Fig.7. qPCR validation for endogenous PHYA and PHYB expression under FR. Plants were exposed to the same cFr as used in Figure 3. A: Endogenous PHYA mRNA levels in WT, phyD and phyE mutant backgrounds were quantified. B: Endogenous PHYB mRNA levels in WT and phyE mutant background were quantified. Error bars with different letters indicate statistical significance difference at the $\mathrm{P}<0.01$ level analysed by two-way ANOVA with LSD post hoc test. 
bioRxiv preprint doi: https://doi.org/10.1101/2021.06.20.449137; this version posted June 22, 2021. The copyright holder for this preprint (which was not certified by peer review) is the author/funder. All rights reserved. No reuse allowed without permission.

Fig.1.

pPHYA:LUC

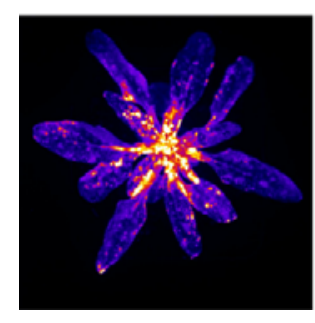

pPHYB:LUC

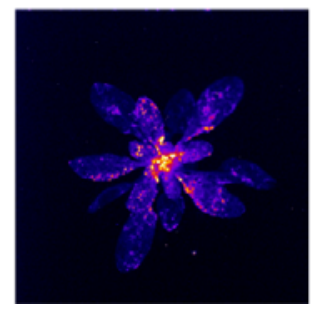

pPHYC:LUC

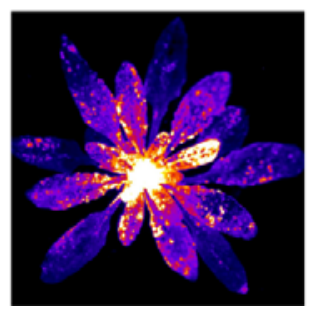

pPHYD:LUC

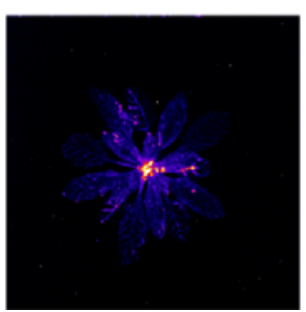

pPHYE:LUC

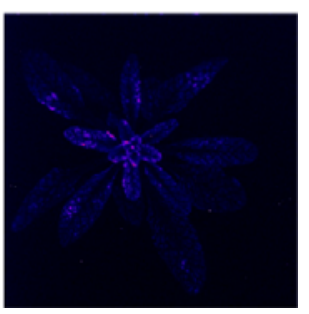


Fig.2.
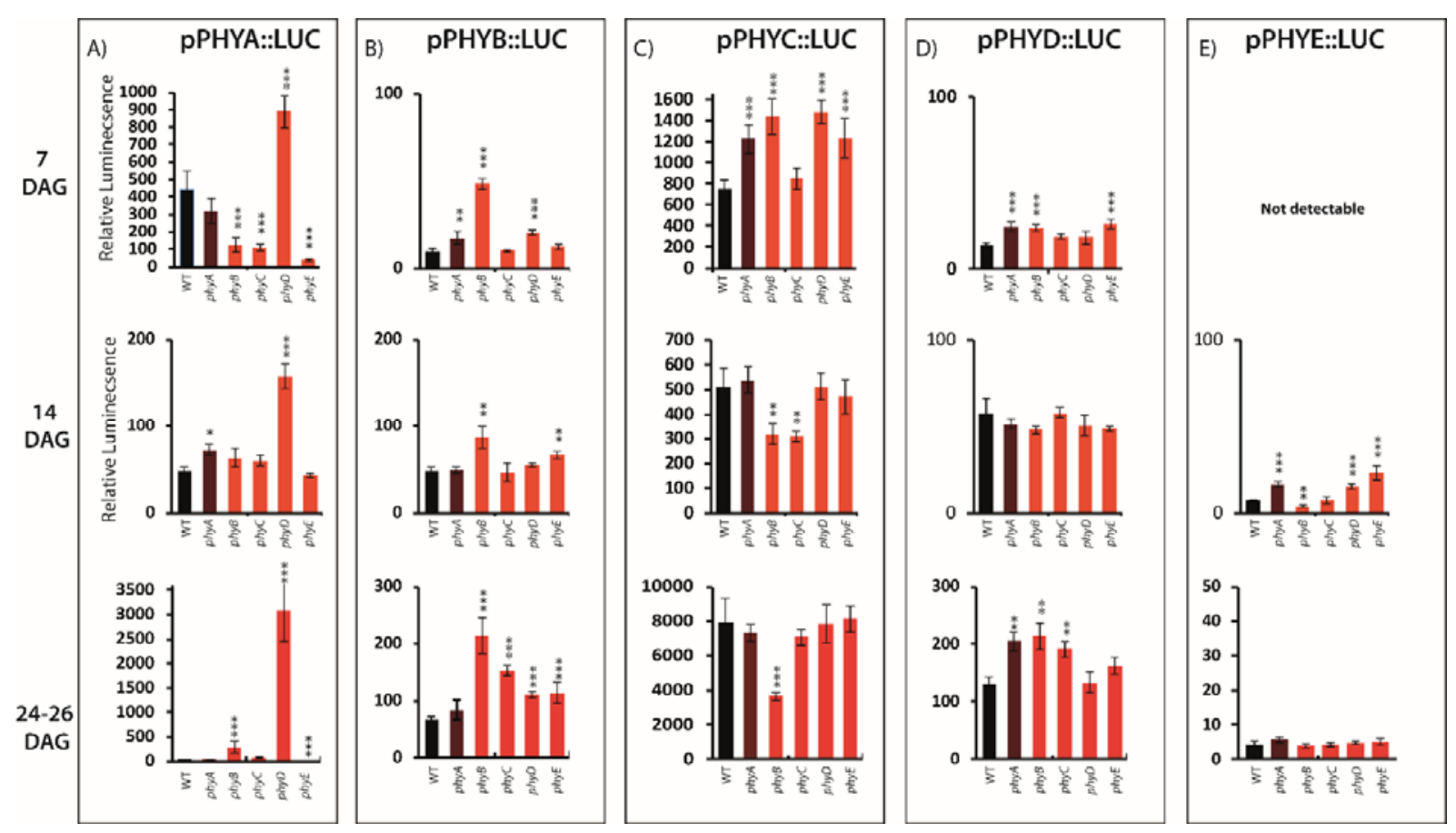
Fig.3.

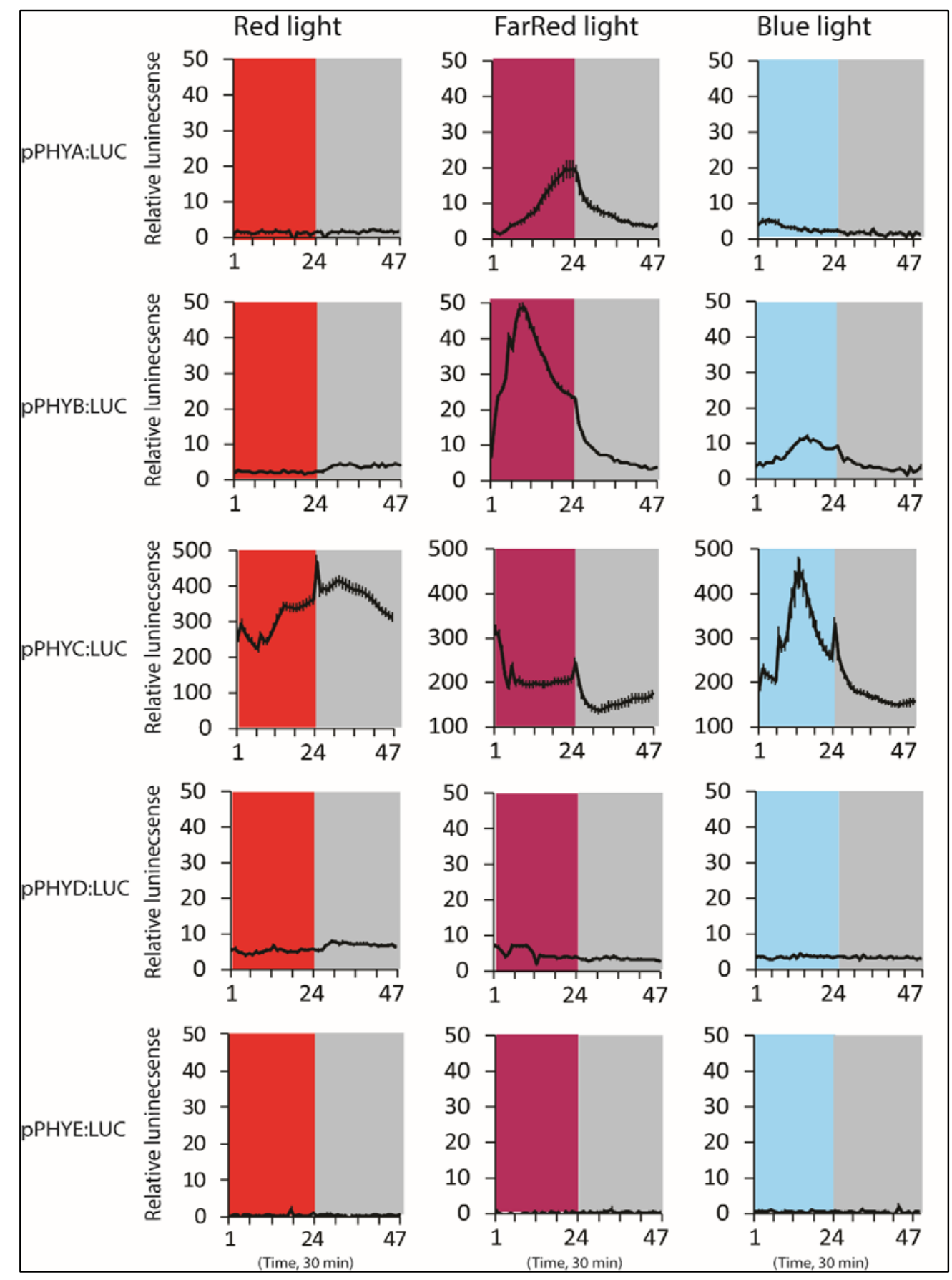


Fig.4.
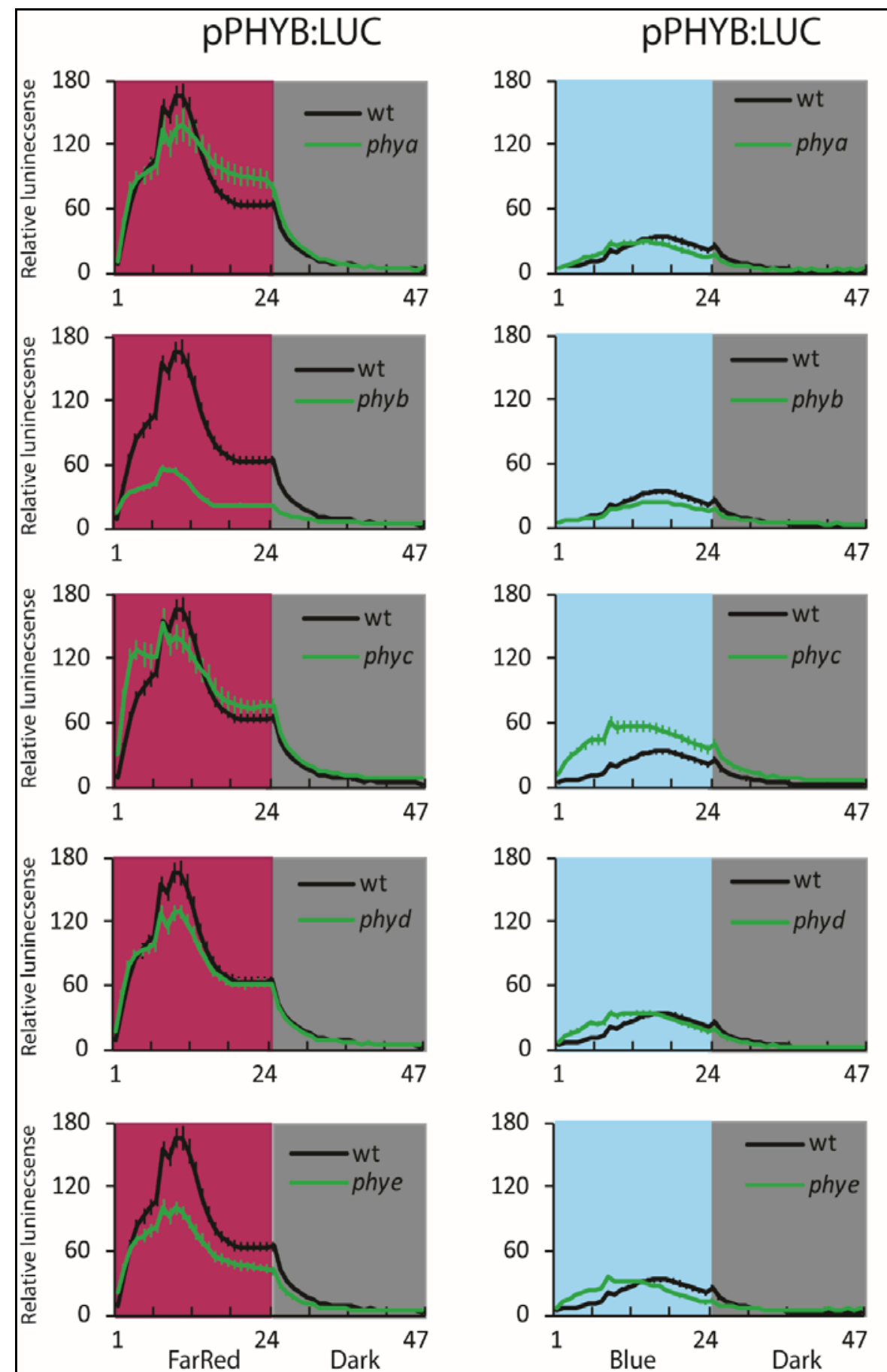

(Time, $30 \mathrm{~min}$ )

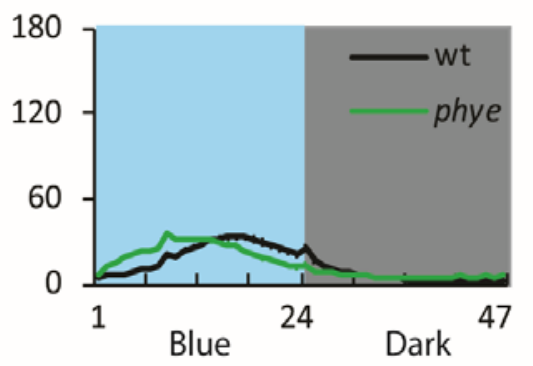

(Time, $30 \mathrm{~min}$ ) 
Fig.5.
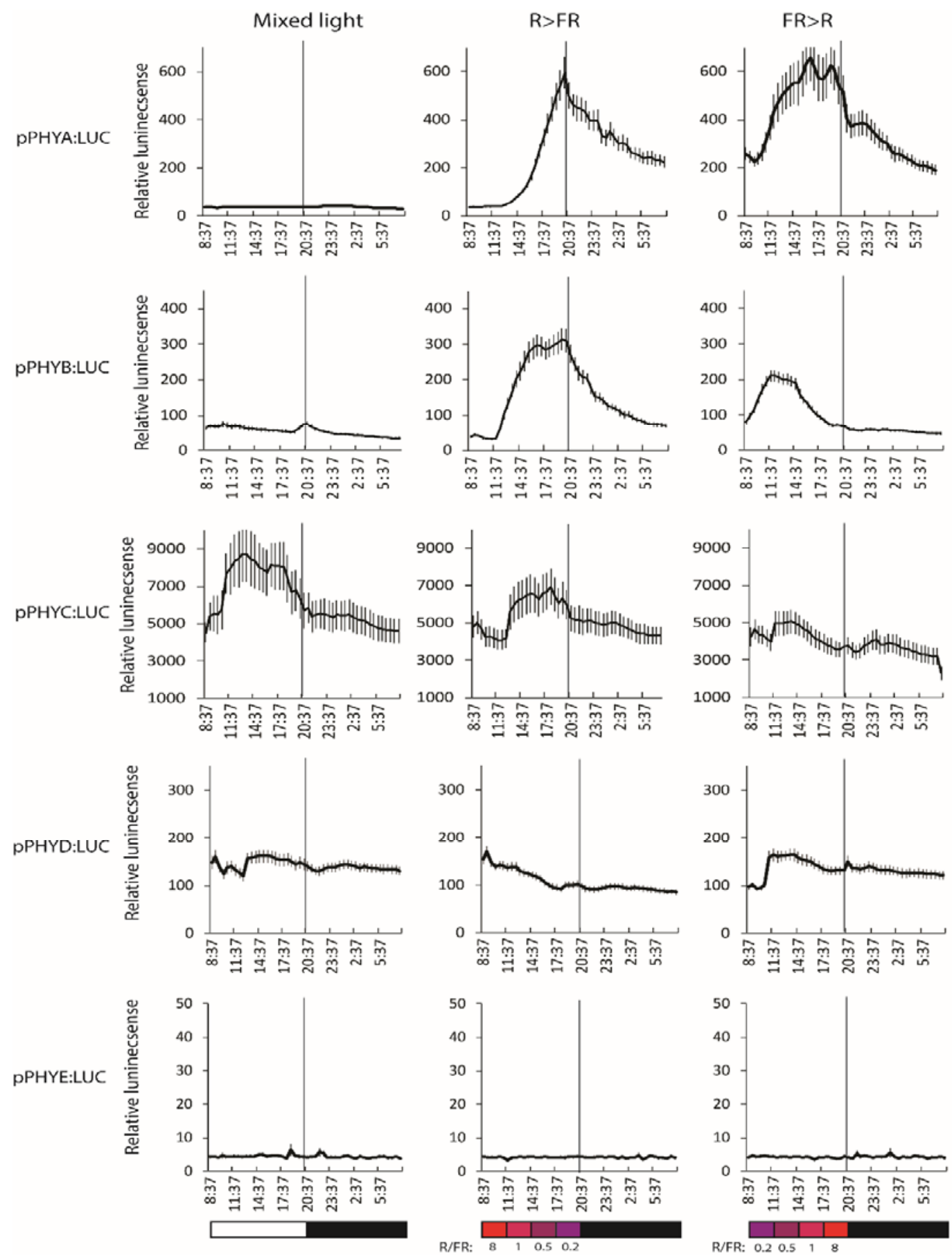
Fig.6.

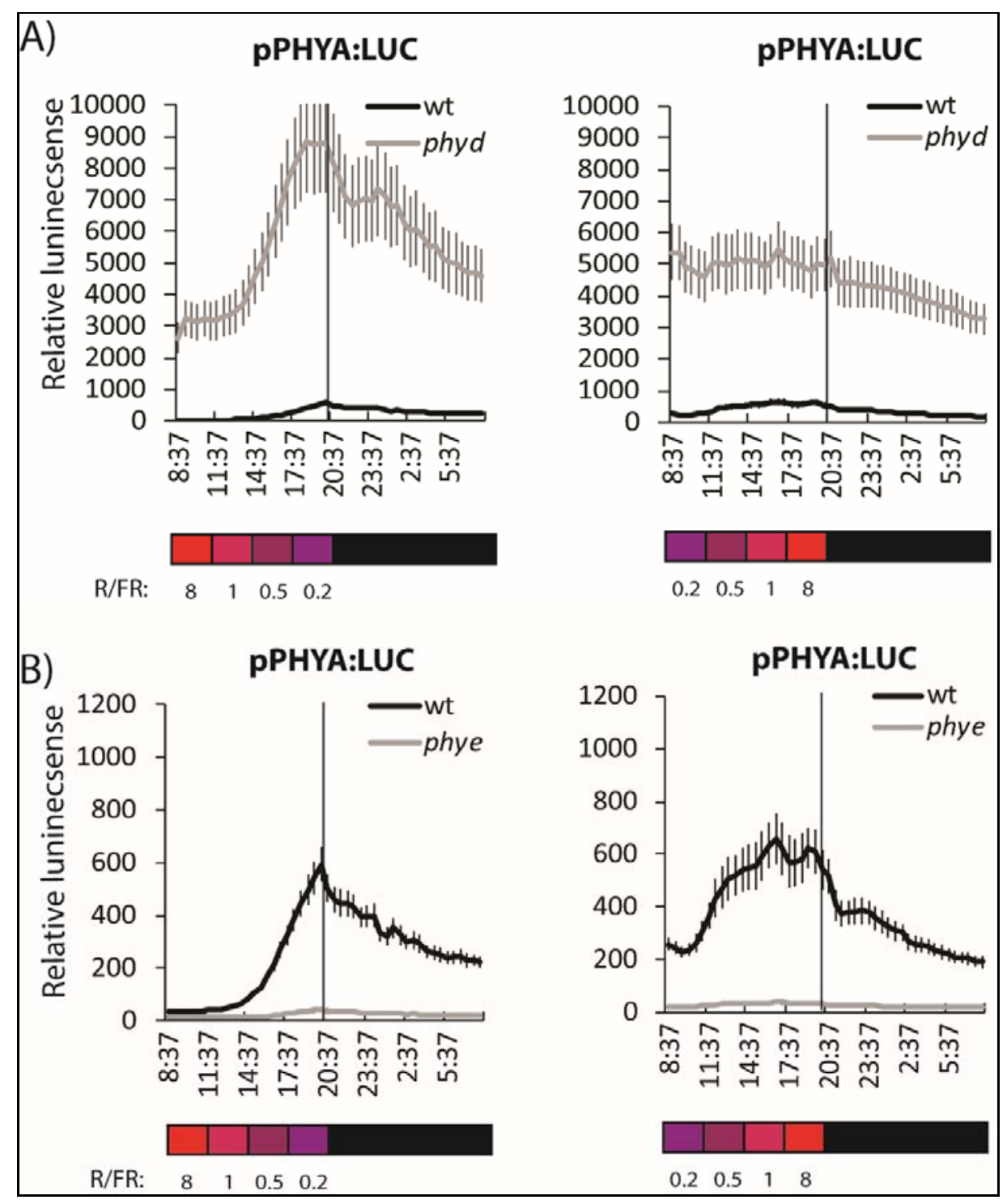


bioRxiv preprint doi: https://doi.org/10.1101/2021.06.20.449137; this version posted June 22, 2021. The copyright holder for this preprint (which was not certified by peer review) is the author/funder. All rights reserved. No reuse allowed without permission.

\section{Fig.7. qPCR validation for mutant lines}

A

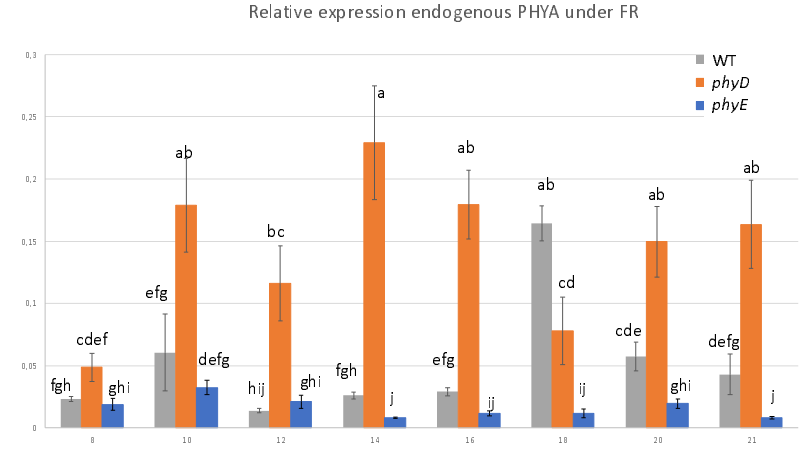

B

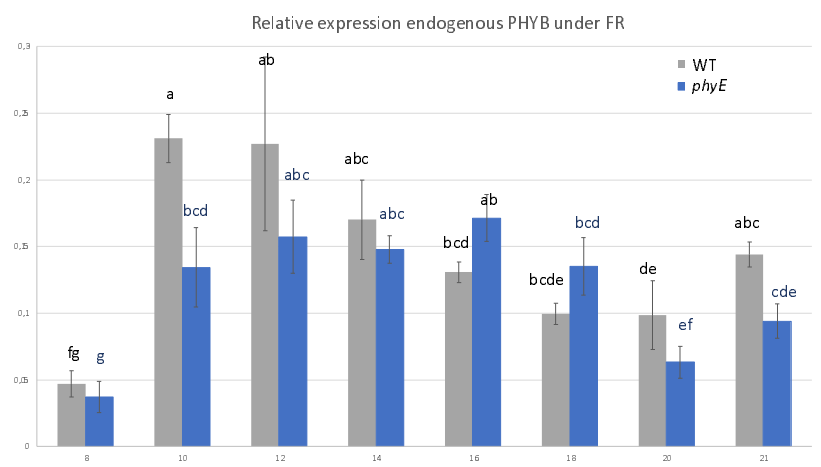




\section{Supplemental Figure legends.}

\section{Fig.S1. Diurnal pPHYB:LUC activity in WT and phy mutant plants under mixed R+B+FR light}

Seeds of PPHYB-LUC reporter in WT and the five single PHY mutant backgrounds were stratified and germinated in growth cabinets under diurnal fluorescent WL (12L/12D). At 14 days after germination seedlings were sprayed with substrate luciferin (1 mM) and one day later placed in LUMINATOR for adjustment under diurnal R+B+FR for one day. Subsequently plants were exposed to light regimes 12 mixed/12D, 12R/12D, followed by 12FR/D and finally 12B/12D. Luciferin (1 mM) solution was sprayed once per day. LUC activity images were obtained every half hour $(7 \mathrm{~min}$. exposure) for each full diurnal cycle. The relative LUC activity was quantified in Image J and corrected for background signal. Number of replicate seedlings for each reporter line: $\mathrm{N}=6$. Error bars represent mean \pm SE.

\section{Fig.S2A-E. pPHY:LUC activity in phy mutant compared WT rosette plants in response to changing R:FR ratios}

Plants were grown under diurnal fluorescent WL (12L/12D). At 25 days after germination plants were sprayed with substrate luciferin (1 $\mathrm{mM}$ ) and one day later placed in LUMINATOR for adjustment under diurnal mixed R+B+FR for one day. Subsequently plants were exposed to a fixed level of R with increasing levels of FR (in blocks of 3 hours), resulting in R:FR ratio's of 8, 1, 0.5 and 0.2. After the following night plants were exposed to the reverse light regime. Luciferin (1 mM) solution was sprayed once per day. LUC activity images were obtained every half hour (7 min. exposure) for each full diurnal cycle. The relative LUC activity was quantified in Image J and corrected for background signal. Number of replicate seedlings for each reporter line: $\mathrm{N}=6$. Error bars represent mea $\pm \mathrm{SE}$.

A: pPHYA:LUC activity in WT and the five phy mutant backgrounds. Note that for the phyD mutant background the scale of relative LUC activity is different. B: PPHYB:LUC activity in WT and the five phy mutant backgrounds. C: PPHYC:LUC activity in WT and the five phy mutant backgrounds. D: pPHYD:LUC activity in WT and the five phy mutant backgrounds. E: pPHYE:LUC activity in WT and the five phy mutant backgrounds. Note that activity is barely above background. 
bioRxiv preprint doi: https://doi.org/10.1101/2021.06.20.449137; this version posted June 22, 2021. The copyright holder for this preprint (which was not certified by peer review) is the author/funder. All rights reserved. No reuse allowed without permission.

\section{Supplemental Figures}

Fig. S1

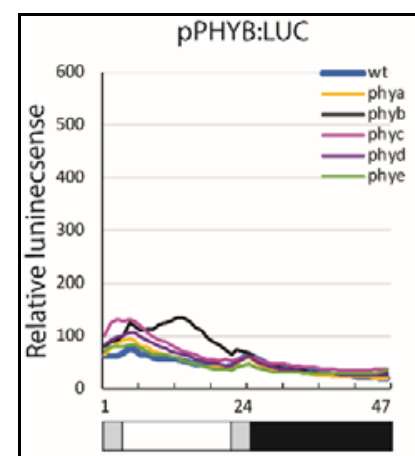

Mixed light

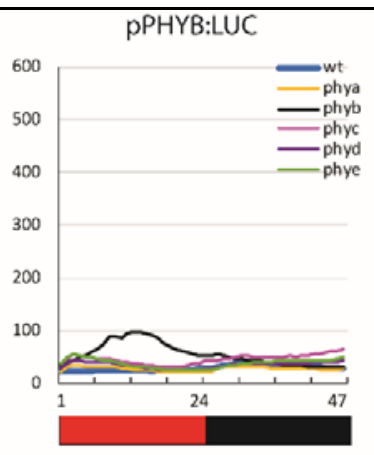

Red light

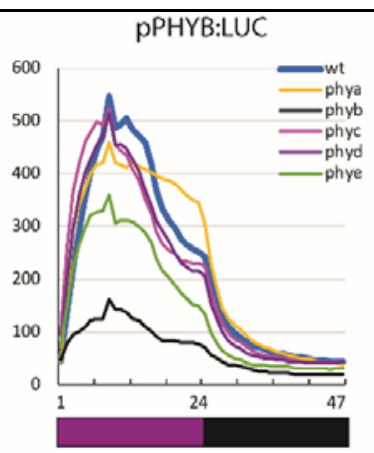

Far-Red light

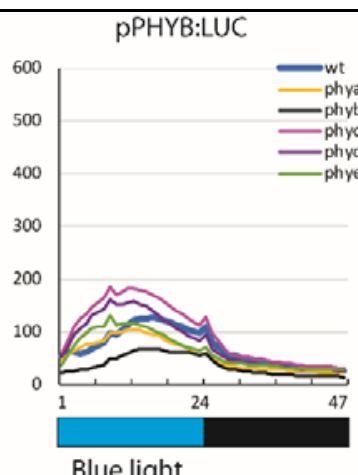

Blue light 


\section{Fig. S2A}
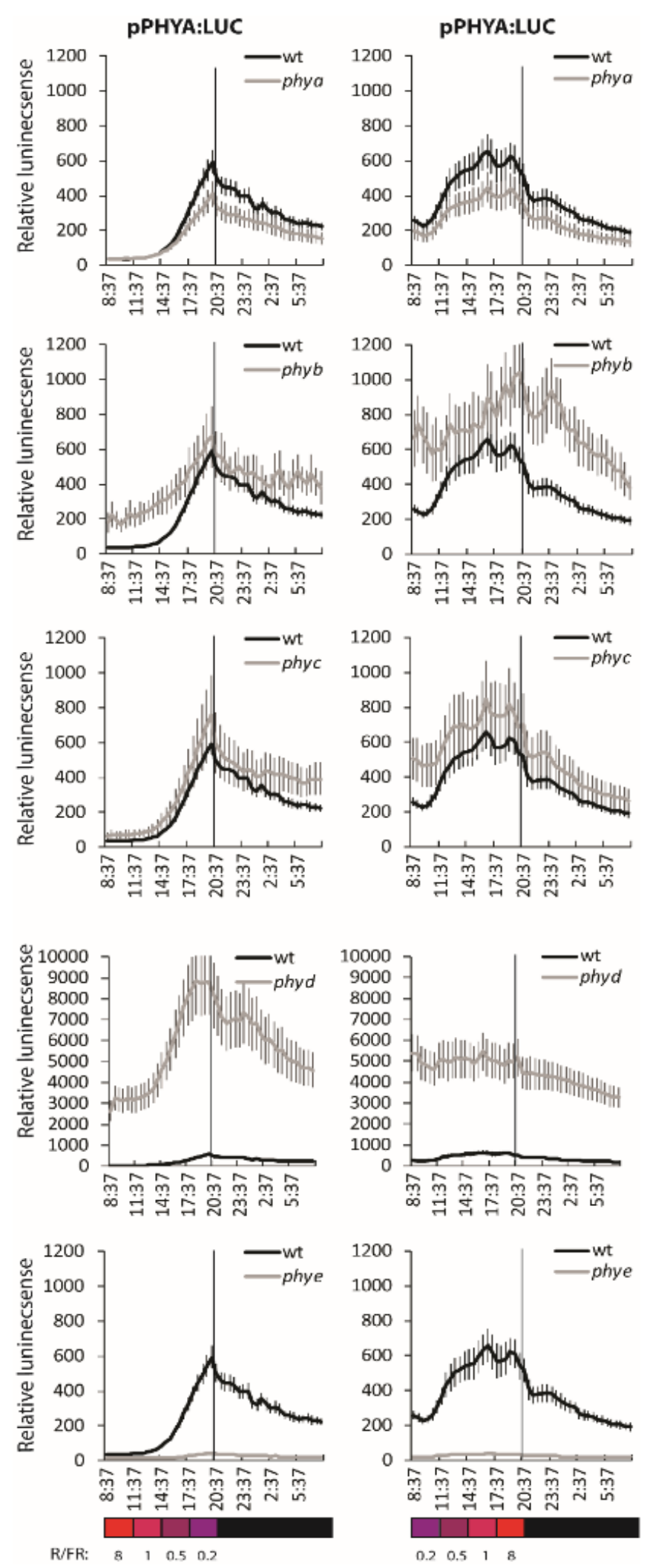


\section{Fig. S2B}
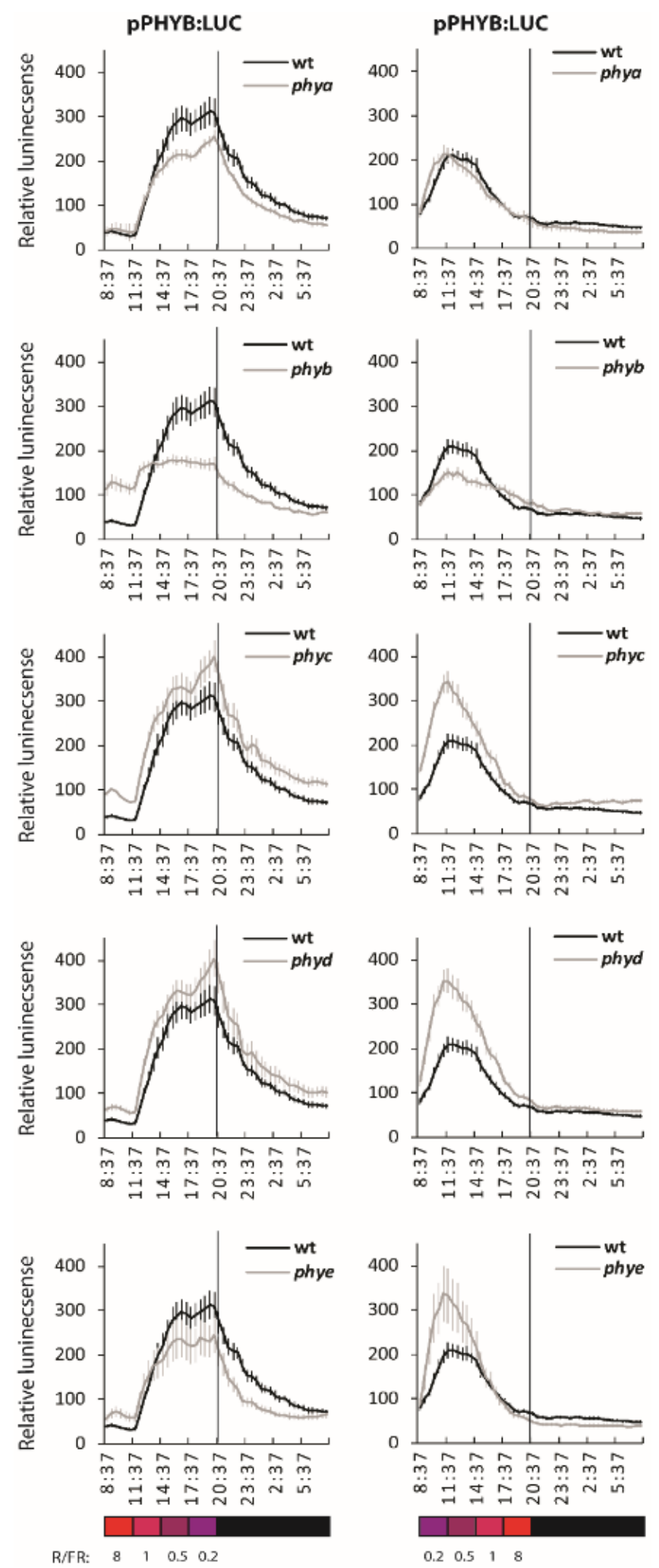


\section{Fig. S2C}
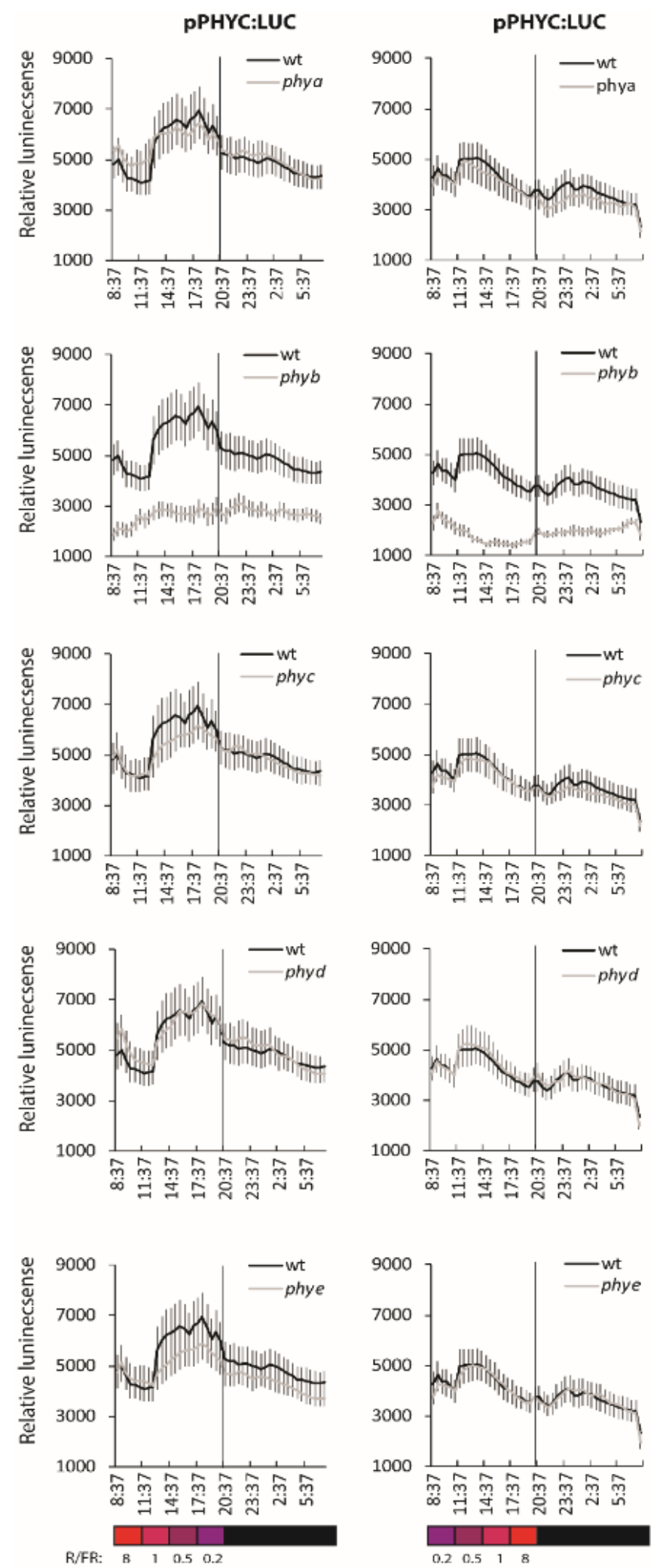
bioRxiv preprint doi: https://doi.org/10.1101/2021.06.20.449137; this version posted June 22, 2021. The copyright holder for this preprint (which was not certified by peer review) is the author/funder. All rights reserved. No reuse allowed without permission.

\section{Fig. S2D}
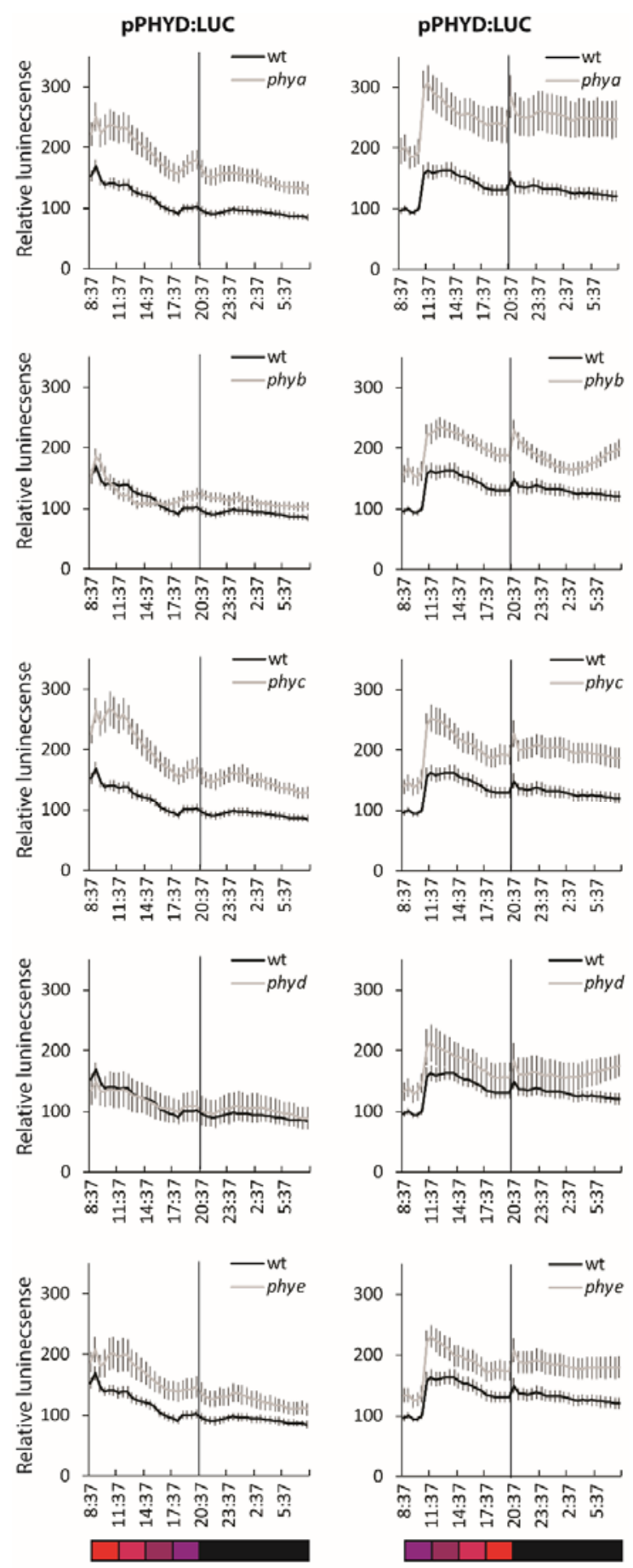

R/FR: $\quad 8 \quad 1 \quad 0.5 \quad 0.2$

$0.2 \quad 0.5 \quad 1 \quad 8$ 
bioRxiv preprint doi: https://doi.org/10.1101/2021.06.20.449137; this version posted June 22, 2021. The copyright holder for this preprint (which was not certified by peer review) is the author/funder. All rights reserved. No reuse allowed without permission.

\section{Fig.S2E}
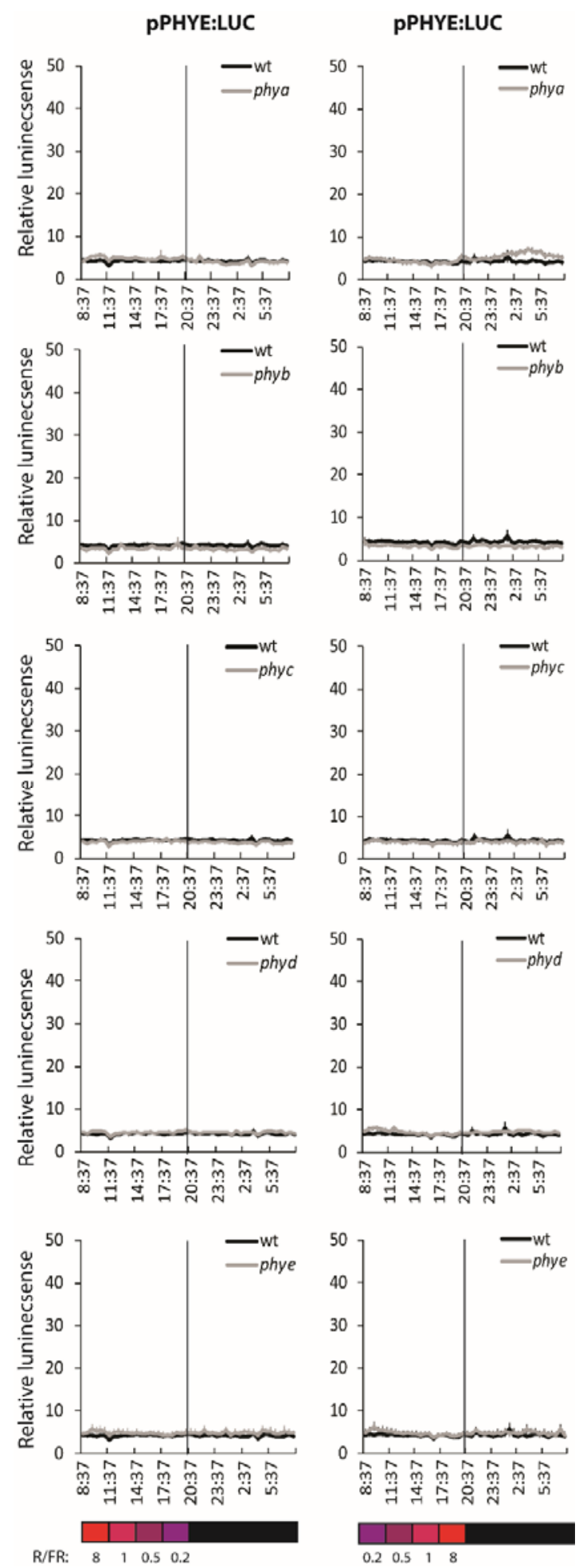

R/FR: $\quad \begin{array}{lllll}8 & 1 & 0.5 & 0.2\end{array}$ 
bioRxiv preprint doi: https://doi.org/10.1101/2021.06.20.449137; this version posted June 22, 2021. The copyright holder for this preprint (which was not certified by peer review) is the author/funder. All rights reserved. No reuse allowed without permission.

\section{Supplemental Tables}

Table-S1. Primers used in this study

\begin{tabular}{|c|c|c|c|}
\hline № & Sequence $\left(5^{\prime}-3^{\prime}\right)$ & Target & Description \\
\hline 1 & $\begin{array}{l}\text { ccagtcagctcagcaattttc-LB } \\
\text { aatgcaaaacatgctagggtg -RB }\end{array}$ & $\begin{array}{c}\text { PHYA } \\
\text { (AT1G09570) }\end{array}$ & Screening for mutant \\
\hline 2 & $\begin{array}{l}\text { ttaggcttacgtagcttcccc -LB } \\
\text { gatggagctgagcatagaacg -RB }\end{array}$ & $\begin{array}{c}\text { PHYC } \\
\text { (AT5G35840) }\end{array}$ & Screening for mutant \\
\hline 3 & $\begin{array}{l}\text { gctttttacacgaatcttgcg - LB } \\
\text { agtctcgcgtcgacagtgtac - RB }\end{array}$ & $\begin{array}{c}\text { PHYD } \\
\text { (AT4G 16250) }\end{array}$ & Screening for mutant \\
\hline 4 & $\begin{array}{l}\text { aaagaggcggtctagttcagc -LB } \\
\text { tatcagtggttaaacccgtcg -RB }\end{array}$ & $\begin{array}{c}\text { PHYE } \\
\text { (AT4G 18130) }\end{array}$ & Screening for mutant \\
\hline 5 & attttgccgatttcggaac -LB & SALK T-DNA & Screening for mutant \\
\hline 6 & $\begin{array}{l}\text { tagcatctgaatttcataaccaatctcgatacac - LB } \\
\text { agagatacgccctggttcct }-\mathrm{F}\end{array}$ & SAIL T-DNA & Screening for mutant \\
\hline 7 & $\begin{array}{l}\text { ctgttgagcaattcacgttca }-\mathrm{R} \\
\text { tccactgggtattgtgtcgc }-\mathrm{F}\end{array}$ & LUC & qPCR \\
\hline 8 & agctatctcctgcaggtgga $-R$ & PHYA & qPCR \\
\hline 9 & $\begin{array}{l}\text { cgttgggtgttgctcctagt }-\mathrm{F} \\
\text { gataccccgcatcgcctaaa }-\mathrm{R}\end{array}$ & PHYB & qPCR \\
\hline 10 & $\begin{array}{l}\text { tccgccatgaagtgaaggac }-F \\
\text { ccgaattcgctgcaatccag }-R\end{array}$ & PHYC & $\mathrm{qPCR}$ \\
\hline 11 & $\begin{array}{l}\text { cgattcctccgtaccagagc }-F \\
\text { tttcccgcgcattttcactg }-R\end{array}$ & PHYD & $\mathrm{qPCR}$ \\
\hline 12 & $\begin{array}{l}\text { attgaaaccgcaactgcacc }-\mathrm{F} \\
\text { tcatcggcaagtgacttccc }-\mathrm{R}\end{array}$ & PHYE & qPCR \\
\hline 13 & $\begin{array}{l}\text { ccatcgacagtgctgatcca- } \mathrm{F} \\
\text { ccattgggtgacacttttggt-R }\end{array}$ & AT2G39960 & Housekeeping for $\mathrm{qPCR}$ \\
\hline
\end{tabular}


bioRxiv preprint doi: https://doi.org/10.1101/2021.06.20.449137; this version posted June 22, 2021. The copyright holder for this preprint (which was not certified by peer review) is the author/funder. All rights reserved. No reuse allowed without permission.

Table-S2. List of reporter lines were used in study. The PPHY:LUC reporter was created in Col-O and its crossed with different mutant background lines.

\begin{tabular}{|c|c|}
\hline LUC reporter lines, constructs & Description \\
\hline pPHYA:LUC ${ }^{\text {WT }}$ & pPHYA:LUC reporter in Col-0 \\
\hline pPHYA:LUC $C^{\text {phyA }}$ & pPHYA:LUC reporter crossed to phyA mutant \\
\hline pPHYA:LUC $C^{\text {phy-9 }}$ & pPHYA:LUC reporter crossed to phyB- 9 mutant \\
\hline pPHYA:LUC ${ }^{\text {phyc }}$ & pPHYA:LUC reporter crossed to phyC mutant \\
\hline pPHYA:LUC $C^{\text {phD }}$ & pPHYA:LUC reporter crossed to phyD mutant \\
\hline pPHYA:LUC ${ }^{\text {phyE }}$ & pPHYA:LUC reporter crossed to phyE mutant \\
\hline pPHYB:LUC ${ }^{\text {wT }}$ & pPHYB:LUC reporter in Col-0 \\
\hline pPHYB:LUC $C^{\text {phyA }}$ & pPHYB:LUC reporter crossed to phyA mutant \\
\hline pPHYB:LUC $C^{\text {phyB-g }}$ & pPHYB:LUC reporter crossed to phyB- 9 mutant \\
\hline pPHYB:LUC $C^{\text {phyc }}$ & pPHYB:LUC reporter crossed to phyC mutant \\
\hline pPHYB:LUC $C^{\text {phD }}$ & pPHYB:LUC reporter crossed to phyD mutant \\
\hline pPHYB:LUC & pPHYB:LUC reporter crossed to phyE mutant \\
\hline pPHYC:LUC ${ }^{\text {WT }}$ & pPHYC:LUC reporter in Col-0 \\
\hline pPHYC:LUC ${ }^{\text {phyA }}$ & pPHYC:LUC reporter crossed to phyA mutant \\
\hline pPHYC:LUC $C^{\text {phyB-g }}$ & pPHYC:LUC reporter crossed to phyB-9 mutant \\
\hline pPHYC:LUC $C^{\text {phyc }}$ & pPHYC:LUC reporter crossed to phyC mutant \\
\hline pPHYC:LUC ${ }^{p h D}$ & pPHYC:LUC reporter crossed to phyD mutant \\
\hline pPHYC:LUC & pPHYC:LUC reporter crossed to phyE mutant \\
\hline pPHYD:LUC ${ }^{W T}$ & pPHYD:LUC reporter in Col-0 \\
\hline pPHYD:LUC ${ }^{\text {phyA }}$ & pPHYD:LUC reporter crossed to phyA mutant \\
\hline pPHYD:LUC ${ }^{\text {phyB-9 }}$ & PPHYD:LUC reporter crossed to phyB-9 mutant \\
\hline pPHYD:LUC phyc & pPHYD:LUC reporter crossed to $p h y C$ mutant \\
\hline pPHYD:LUC ${ }^{p h D}$ & pPHYD:LUC reporter crossed to phyD mutant \\
\hline pPHYD:LUC ${ }^{\text {phyE }}$ & pPHYD:LUC reporter crossed to phyE mutant \\
\hline pPHYE:LUC ${ }^{\text {wT }}$ & pPHYE:LUC reporter in Col-o \\
\hline pPHYE:LUC phyA & PPHYE:LUC reporter crossed to phyA mutant \\
\hline pPHYE:LUC phyB-9 $^{\text {phe }}$ & PPHYE:LUC reporter crossed to $p h y B-9$ mutant \\
\hline pPHYE:LUC ${ }^{\text {phyc }}$ & PPHYE:LUC reporter crossed to phyC mutant \\
\hline pPHYE:LUC ${ }^{\text {phD }}$ & pPHYE:LUC reporter crossed to phyD mutant \\
\hline PPHYE:LUC $C^{\text {phy }}$ & PPHYE:LUC reporter crossed to phyE mutant \\
\hline
\end{tabular}

$\begin{array}{ll}\text { Plasmid notes } & \text { Ref } \\ H y g^{\mathrm{R}} / \mathrm{pPCVH} & \text { In study } \\ H y g^{\mathrm{R}} / \mathrm{pPCVH} & \text { In study } \\ H y g^{\mathrm{R}} / \mathrm{pPCVH} & \text { In study } \\ H y g^{\mathrm{R}} / \mathrm{pPCVH} & \text { In study } \\ H y g^{\mathrm{R}} / \mathrm{pPCVH} & \text { In study } \\ H y g^{\mathrm{R}} / \mathrm{pPCVH} & \text { In study } \\ H y g^{\mathrm{R}} / \mathrm{pPCVH} & \text { In study } \\ H y g^{\mathrm{R}} / \mathrm{pPCVH} & \text { In study } \\ H y g^{\mathrm{R}} / \mathrm{pPCVH} & \text { In study } \\ H y g^{\mathrm{R}} / \mathrm{pPCVH} & \text { In study } \\ H y g^{\mathrm{R}} / \mathrm{pPCVH} & \text { In study } \\ H y g^{\mathrm{R}} / \mathrm{pPCVH} & \text { In study } \\ H y g^{\mathrm{R}} / \mathrm{pPCVH} & \text { In study } \\ H y g^{\mathrm{R}} / \mathrm{pPCVH} & \text { In study } \\ H y g^{\mathrm{R}} / \mathrm{pPCVH} & \text { In study } \\ H y g^{\mathrm{R}} / \mathrm{pPCVH} & \text { In study } \\ H y g^{\mathrm{R}} / \mathrm{pPCVH} & \text { In study } \\ H y g^{\mathrm{R}} / \mathrm{pPCVH} & \text { In study } \\ H y g^{\mathrm{R}} / \mathrm{pPCVH} & \text { In study } \\ H y g^{\mathrm{R}} / \mathrm{pPCVH} & \text { In study } \\ H y g^{\mathrm{R}} / \mathrm{pPCVH} & \text { In study } \\ H y g^{\mathrm{R}} / \mathrm{pPCVH} & \text { In study } \\ H y g^{\mathrm{R}} / \mathrm{pPCVH} & \text { In study } \\ H y g^{\mathrm{R}} / \mathrm{pPCVH} & \text { In study } \\ H y g^{\mathrm{R}} / \mathrm{pPCVH} & \text { In study } \\ H y g^{\mathrm{R}} / \mathrm{pPCVH} & \text { In study } \\ H y g^{\mathrm{R}} / \mathrm{pPCVH} & \text { In study } \\ H y g^{\mathrm{R}} / \mathrm{pPCVH} & \text { In study } \\ H y g^{\mathrm{R}} / \mathrm{pPCVH} & \text { In study } \\ H y g^{\mathrm{R}} / \mathrm{pPCVH} & \text { In study }\end{array}$

